\title{
Spatiotemporal 7q11.23 Protein Network Implicates the GTF2I-PRKDC-DDR Pathway During Early-Fetal Brain Development in Psychiatric Diseases
}

\section{Guan Ning Lin ( $\square$ nickgnlin@sjtu.edu.cn )}

Shanghai Jiao Tong University

\section{Liang Chen}

Shanghai Mental Health Center, Shanghai Jiao Tong University School of Medicien, School of

Biomedical Engineering, Shanghai Jiao Tong University

\section{Weidi Wang}

Shanghai Jiao Tong University School of Biomedical Engineering

\section{Wenxiang Cai}

Shanghai Jiao Tong University School of Medicine Affiliated Shanghai Mental Health Center: Shanghai

Mental Health Center

\section{Weichen Song}

Shanghai Jiao Tong University School of Biomedical Engineering

\section{Wei Qian}

Shanghai Mental Health Center, Shanghai Jiao Tong University School of Medicine, School of Biomedical Engineering, Shanghai Jiao Tong University

\section{Research}

Keywords: PPIs, spatiotemporal network, Chromosome 7q11.23, GTF2I

Posted Date: October 26th, 2020

DOI: https://doi.org/10.21203/rs.3.rs-93461/v1

License: (c) (i) This work is licensed under a Creative Commons Attribution 4.0 International License. Read Full License 
3 Spatiotemporal $7 q 11.23$ protein network implicates the GTF2I-PRKDC-DDR pathway during early-fetal brain development in psychiatric diseases

5

6 Liang Chen ${ }^{1}$, Weidi Wang ${ }^{1,2}$, Wenxiang $\mathrm{Cai}^{\mathbf{1}}$, Weichen Song ${ }^{1}$, Wei Qian ${ }^{1}$, Guan Ning $7 \quad \operatorname{Lin}^{1,2 *}$

8

* Corresponding author: nickgnlin@sjtu.edu.cn Biomedical Engineering, Shanghai Jiao Tong University, Shanghai 200030, China 


\section{Abstract}

Background: Recurrent deletions and duplications of chromosome 7q11.23 copy number variants (CNVs) are associated with several psychiatric disorders. Previous works showed GTF2I associated with Williams-Beuren syndrome, but pathways affected by GTF2I are poorly defined. Although phenotypic abnormalities have been observed in patients and animal models, the targeted human brain regions, developmental stages, protein networks, and signaling pathways, influenced by this CNV remain unclear.

Results: Topological changes were observed in protein-protein interaction (PPI) networks throughout different stages of brain development. Early and late fetal periods of development in the cortex, striatum, hippocampus, and amygdale were observed as the vital periods and regions for $7 \mathrm{q} 11.23 \mathrm{CNV}$ proteins. As a driver gene, GTF2I interacted with PRKDC and BRCA1 to involve in DNA Damaging Response (DDR) pathway. The physical interaction between GTF2I with PRKDC was confirmed experimentally by the liquid chromatography-tandem mass spectrometry (LC-MS/MS).

Conclusion: We identified that striatum, hippocampus, and amygdala are crucial regions for establishing connectivity between $7 \mathrm{q} 11.23$ proteins and their partners in early and late fetal periods. Our results suggested that GTF2I-PRKDC-DDR and GTF2I-BRCA1-DDR pathway is crucial for the 7q11.23 CNV genes to contribute to the pathogenesis of psychiatric diseases. 
Keywords: PPIs, spatiotemporal network, Chromosome 7q11.23, GTF2I

\section{Background}

Copy number variants $(\mathrm{CNVs})$ are alterations in the number of copies of a genomic DNA region; these alterations can include duplications and deletions [1, 2]. CNVs have been shown to act as significant risk factors for complex disorders (e.g., neurodevelopmental and autoimmune) in humans [3-5]. Previous studies have shown that the duplication or deletion of $7 \mathrm{q} 11.23$ has been associated with several psychiatric disorders $[6,7]$. For example, the duplication of $7 \mathrm{q} 11.23$ can lead to the development of autism spectrum disorder (ASD) or attention deficit hyperactivity disorder [8-10], and the deletion of $7 \mathrm{q} 11.23$ would cause a specific neurodevelopmental disorder, Williams-Beuren syndrome (WBS). In addition, the microcephaly has been observed recurrently in carriers of the 7q11.23 deletion [11], while, the macrocephaly clinical phenotype has been observed sometimes in duplication carriers [12].

The intricacy and highly polygenic characteristics of psychiatric disorders hamper our ability to identify the underlying mechanisms of action with regard to their genetic risk factors. One way of addressing this issue is by analyzing omics data to identify a diverse range of genetic causes. For example, a previous transcriptomic study of the 
7q11.23 CNV in patient-derived induced pluripotent stem cell (iPSC) lines suggested alterations in gene expression, related signaling pathways, and molecular networks [13]. Furthermore, one gene with a 7q11.23 deletion/duplication, general transcription factor II-I (GTF2I), was found to play an important role in the differentiation of iPSCs into disease-relevant lineages [13]. Although a related molecular network was established in this previous study, the network was static and only one developmental period was investigated.

A different approach of addressing this issue is based on creating animal or cell models to help identify the related molecular and cellular mechanisms. For instance, mice with a heterozygous deletion of GTF2I or GTF2IRD1 show defects in skeletal and craniofacial. [14]. In addition, the embryos of these mice present with a small head; this is consistent with the clinical phenotype of patients carrying a $7 q 11.23$ deletion. Nevertheless, the signaling pathways affected by this CNV remain unknown. Replication factor C subunit 2 (RFC2), another 7q11.23 gene, encodes a subunit of the replication factor $\mathrm{C}$ (RFC) complex [15] and is known to play a role in ATR signaling $[16,17]$. Haploinsufficiency for RFC2 leaded to G2/M checkpoint arrest after DNA damage [18]. However, little is known about how genes with the 7q11.23 deletion/duplication may affect the occurrence of neurodevelopmental disorders because these genes are involved not only in multiple developmental stages but also within different tissues. Hence, genes exhibiting 7q11.23 deletion/duplication play 
different roles in different developmental stages and different anatomic structures.

CNVs have been reported to modulate gene expression, which, ultimately, might affect disease predisposition or clinical phenotypes [19, 20]. Several researches have investigated $\mathrm{CNV}$ pathogenesis in psychiatric disorders by constructing a static topological network based on a single developmental stage [21]. Within different developmental periods, protein expression can change, as can protein-protein interactions (PPIs) [22]. Nevertheless, protein expression is a dynamic process that can occur in a different manner across different anatomical areas [23, 24]. Analyses of molecular networks can reveal biological modularity and complex signaling pathways $[25,26]$. Previous studies discovered the pathogenesis of CNVs by constructing dynamic protein-protein interaction (PPI) networks according to alterations of protein expression in different anatomical areas and during different developmental periods $[27,28]$.

In addition, multiple studies mentioned above focused only on one or two genes and were unable to demonstrate how the $7 \mathrm{q} 11.23 \mathrm{CNV}$ is involved in brain development. Although phenotypic abnormalities have been observed in patients and animal models, the targeted brain regions, periods, protein networks, and signaling pathways, influenced by this CNV remain unclear. To overcome these knowledge gaps, we 
constructed a dynamic spatiotemporal network of genes exhibiting the 7q11.23 deletion/duplication by integrating data from the human brain developmental transcriptome with physical interactions of $7 \mathrm{q} 11.23$ proteins.

Our study demonstrated that $7 \mathrm{q} 11.23$ proteins interact with their partners mainly in three spatiotemporal intervals, and that the interaction patterns change across these intervals. We identified that striatum, hippocampus, and amygdala are crucial regions for the interactions between $7 \mathrm{q} 11.23$ proteins and their partners in early and late fetal periods. In addition, our results indicated that GTF2I plays a key role in a dynamic network by interacting with DNA-dependent protein kinase catalytic subunit (PRKDC) and Breast cancer type 1 susceptibility protein (BRCA1). We undertook co-immunoprecipitation (Co-IP) experiments and liquid chromatography-tandem mass spectrometry (LC-MS/MS) to identify the interactions between GTF2I and PRKDC.

\section{Results}

\section{Construction of a spatiotemporal interaction network for $7 q 11.23$}

In general, PPIs take place only if proteins are located in the same cell components simultaneously [29, 30]. A range of studies has demonstrated robust correlations between higher co-expression and protein interaction across most cellular conditions 
120 [31]. Thus, the combination of data relating to gene expression and protein interaction

121 could reveal protein interactions at different developmental stages and in different

122 anatomical regions. To investigate the regulatory roles of the $7 \mathrm{q} 11.23 \mathrm{CNV}$ in the

123 development of the human brain, we extracted 21 brain-expressed genes located on

124 the chromosomal region of $7 \mathrm{q} 11.23$ encompassing $\sim 1.4 \mathrm{Mb}$ (chromosome 7:

125 72.4-73.4 Mb) (Supplementary Table S1) and constructed dynamic networks by

126 integrating spatiotemporal gene co-expressions of the developing human brain with

127 the physical PPIs of 7q11.23 proteins (Fig. 1).

129 We obtained gene expression data in the brain from BrainSpan (www.brainspan.org)

130 and partitioned different regions and periods, as described by Lin and colleagues

131 (Supplementary Table S2) [27]. We defined 32 spatiotemporal intervals based on

132 eight periods of brain development (P1-P8) and four brain regions (R1-R4) and

133 excluded P3R4 (P3, early mid-fetal; R4, mediodorsal nucleus of the thalamus and

134 cerebella cortex) due to insufficient data for analyses. Three control datasets were

135 used for controlling biases in the analyses: (i) physically interacting partners

136 interacting with proteins of common CNVs identified in the 1000 Genomes Project;

137 (ii) all possible pairs between7q11.23 CNV genes and brain expressed genes; and (iii)

138 all brain-expressed proteins interacting with their physically interacting partners. 

periods

To identify significant enrichment of connectivity for $7 \mathrm{q} 11.23 \mathrm{CNV}$, fractions of

143 co-expression interacting pairs were calculated for $7 \mathrm{q} 11.23$ proteins and three control

144 datasets across 31 spatiotemporal intervals. After false-discovery rate (FDR)

145 correction for multiple testing, we observed significantly more co-expressed

146 interacting pairs in two spatiotemporal network intervals than in all three controls:

147 P1R1 (P1: early fetal; R1: parietal, temporal, and occipital cortex; Fisher's exact test;

$148 \mathrm{p}=1.05 \times 10^{-6}, \mathrm{p}=3.41 \times 10^{-15}, \mathrm{p}=4.82 \times 10^{-6}$ ) and P1R3 (P1: early fetal; R3:

149 amygdala, hippocampus, and striatum; Fisher's exact test; $\mathrm{p}=1.41 \times 10^{-8}, \mathrm{p}=$

$1503.41 \times 10^{-15}, \mathrm{p}=2.19 \times 10^{-15}$ (Fig. 2). Another spatiotemporal interval, P4R3 (P4: late

151 fetal; R3: amygdala, hippocampus, and striatum), showed a significantly more

152 co-expressing interacting pairs in $7 \mathrm{q} 11.23 \mathrm{CNV}$ network than two of control networks:

153 (i) co-expressing physical PPIs of common CNVs $\left(\mathrm{p}=4.34 \times 10^{-2}\right)$ and (ii) possible

154 pairs between proteins with the $7 \mathrm{q} 11.23 \mathrm{CNV}$ and all brain-expressed proteins ( $\mathrm{p}$ $\left.155=2.24 \times 10^{-7}\right)$ (Fig. 2).

157 Similarities and differences between the 7q11.23 networks

158 Next, we investigated similarities between the three significant networks, by 159 identifying their convergence by computing the fraction of shared proteins in these 
networks. We observed that 13 of $23(56 \%)$ 7q11.23-CNV proteins and 71 of 290

$161(24.5 \%)$ of their co-expressed interacting partners were shared by all three networks

162 in three intervals: P1R1 (P1: early fetal; R1: parietal, temporal, and occipital cortex),

163 P1R3 (P1: early fetal; R3: amygdala, hippocampus, and striatum) and P4R3 (P4: late

164 fetal; R3: amygdala, hippocampus, and striatum) (Fig. 3). Next, we undertook

165 analyses of functional enrichments on shared CNV genes and shared interacting

166 partners using Metascape (http://metascape.org) [32]. The top-three significant

167 categories for the "biological process" were "signal transduction by p53 class

168 mediator", "regulation of cell cycle process", and "mRNA processing (Fig. 3).

170 Next, we compared connectivity of co-expressed interacting protein pairs either

171 within the same developmental period (early fetal, P1) or within the same brain region

172 (R3) to identify both topological and functional differences between the

173 spatiotemporal 7q11.23 networks. As noted, we have identified three spatiotemporal

174 networks with significantly enriched co-expressed PPI pairs across different brain

175 regions (R1 and R3) within the same developmental period (early fetal, P1) and also

176 across different developmental periods (early fetal (P1) and late fetal (P4)) within the

177 same region (R3). Network changes were assessed by calculating the fractions of

178 co-expressed PPI pairs that were unique to one network against the fractions of

179 co-expressed PPI pairs that were shared among networks (Fig. 4). We noted a

180 significant difference between identical region within different developmental periods 
(P1R3 and P4R3; ANOVA; $\mathrm{p}=2.95 \times 10^{-16}$ ) (Supplementary Table S3). In contrast, no significant difference was observed between same period within different regions (P1R1 and P1R3, ANOVA; $\mathrm{p}=0.349)($ Supplementary able S4).

\section{7q11.23 networks involved in the regulation of DNA repair, DNA replication, and}

\section{the cell cycle}

Next, we set to investigate the biological functions of $7 q 11.23$ proteins and their partners within three dynamic 7q11.23 networks, P1R1, P1R3 and P4R3. Hence, we analyzed functional enrichment of the pathways of related genes using the Gene Ontology (GO) and Kyoto Encyclopedia of Genes and Genomes (KEGG). For 7q11.23 proteins and their partners from the P1R1 network, the top-three significant terms for the biological process were "DNA repair", "regulation of cell cycle process", and "double-strand break repair" (Fig. 5). The top-three terms for the biological processes involving 7q11.23 proteins and partners from the P1R3 network were “DNA-dependent DNA replication", "RNA splicing via transesterification reactions with bulged adenosine as nucleophile", and "regulation of cell cycle process" (Fig. 5). For 7q11.23 proteins and their partners from the P4R3 network, the top-three significant terms were "regulation of DNA metabolic process", "RNA splicing", and "regulation of cellular protein localization" (Fig. 5). Next, we observed that 71 co-expressed and interacting partners of CNV proteins were exclusively from the P4R3 network, not from P1R1 and P1R3 networks, and associated with "signaling 
pathways regulating pluripotency of stem cells (PSCs)", "EGFR tyrosine kinase

203 inhibitor resistance", and "cell cycle", and the "hippo signaling pathway".

204 (Supplementary Fig. S1).

Spatiotemporal networks identified driver gene and the GTF2I-PRKDC-DDR pathway

Of the three significant networks that we identified above, GTF2I possesses the highest radiality value, thus indicating that GTF2I is a driver gene and adopts a central position within these networks (Supplementary table S5). It has been reported that GTF2I heterozygotes exhibit microcephaly and retarded growth [14]. Recent studies have also demonstrated that GTF2I is involved in neurodevelopment $[33,34]$. Importantly, the phenotype observed in mice mirrors that observed in

214 humans [35]. As a driver gene within networks, GTF2I is a crucial contributor to 215 neuropsychiatric disorders [36-38]. Hence, we investigated the interaction pattern of 216 GTF2I across three significant spatiotemporal networks.

218 Seventy-three proteins interacted physically and were co-expressed with GTF2I 219 across three spatiotemporal intervals (Fig. 4). Several of these partners were hub 220 proteins which interacted with several CNV proteins. These hub proteins also 221 interacted physically and were co-expressed with each other, thereby forming one 
functional module (Fig. 6A). These hub partners were PRKDC, BRCA1, ZMYM2,

ZMYM3, HDAC3, RPA1, RPA2, and RPA3. Of these partners, PRKDC possesses the

highest radiality value in the functional module (Supplementary Table S6). GTF2I

interacts with PRKDC, which acts as a "sensor" for double-strand DNA breaks [39,

40]. PRKDC lies within the $8 \mathrm{q} 11.21$ locus and promotes DNA repair via nonhomologous end-joining (NHEJ) [41].

GTF2I also interacts with BRCA1, which is a nuclear phosphoprotein required for the repair of double-strand DNA breaks and homologous recombination [42, 43]. Tanikawa M and colleagues showed that GTF2I proteins bind directly to BRCT (the carboxyl-terminal domain of BRCA1) [44], thus indicating that GTF2I plays an important role in DNA repair. ZMYM2 acts as transcription factor and is involved in DDR [45]. ZMYM3 is a component of histone deacetylase (HDAC)-containing multiprotein complexes. ZMYM3 and HDAC3 involve in a DNA-damage pathway and facilitates DNA repair [46, 47]. Furthermore, RPA1, RPA2, and RPA3, are subunits of the heterotrimeric replication protein A (RPA) complex, which is involved in DNA repair and DNA replication.

PRKDC and BRCA1 exhibited higher levels of connectivity in the early-fetal period 
important role during the early-fetal period. PRKDC and BRCA1 interact with two

243 CNV proteins (GTF2I and RFC2) in P1R1 network. PRKDC interacts with GTF2I

244 and RFC2 within P1R3 network. BRCA1 interacts with three CNV proteins (GTF2I,

245 RFC2 and GTF2IRD1) in P1R3 network. PRKDC interacts with GTF2I in P4R3

246 network. BRCA1 interacts with GTF2I and GTF2IRD in P4R3 network. Within P4R3

247 network, the interactions between PRKDC and BRCA1 with RFC2 were not observed.

248 PRKDC and BRCA1 exhibit a similar interaction pattern during early-fetal and

249 late-fetal periods. The interactions between GTF2I and RFC2 with RPA1 exhibit no

250 change during early-fetal and late-fetal stages.

Validation of the interaction between GTF2I and PRKDC by

\section{immunoprecipitation and LC-MS/MS}

254 Next, we attempted to identify the proteins that interact with GTF2I. Hence, the

255 immunocomplex arising from the immunoprecipitation of the control immunoglobulin

256 G (IgG) antibody or Myc antibody was separated by sodium dodecyl

257 sulfate-polyacrylamide gel electrophoresis (SDS-PAGE), followed by staining with

258 Coomassie brilliant blue (CBB). Several unique protein bands were observed

259 consistently in complexes that were pulled-down by the Myc antibody, but not in the

260 control IgG (supplementary Fig. S2). Then, the interaction between GTF2I and

261 PRKDC was detected by liquid chromatography-tandem mass spectrometry

262 (LC-MS/MS) (Fig. 6B). 


\section{De novo mutations are significantly enriched in spatiotemporal network}

De novo mutations have been implicated in various psychiatric disorders as potential disease risks [48, 49]. Thus, we compared all of the interacting partners and 7q11.23 proteins with the de novo mutations observed in psychiatric diseases. Proteins from the spatiotemporal 7q11.23 network were enriched significantly in ASD genes (FDR-corrected $\mathrm{p}=7.21 \times 10^{-4}$ ). These proteins were also significantly enriched in genes associated with developmental delay (FDR-corrected $\mathrm{p}=0.0045)$ and the target genes for fragile $\mathrm{X}$ mental retardation protein $($ FMRP) $($ FDR-corrected $\mathrm{p}=0.0017)$. There was no significant difference between the entire 7q11.23 network and genes for genes associated with neurodegenerative disease (supplementary table S7).

\section{Discussion}

We constructed a dynamic network for the $7 \mathrm{q} 11.23 \mathrm{CNV}$, which is a crucial risk factor for psychiatric disorders. Importantly, the spatiotemporal network indicated that 7q11.23 CNV genes played a crucial role in three intervals: P1R1 (early fetal, frontal lobe), P1R3 (early fetal, striatum, hippocampus and amygdale) and P4R3 (late fetal, striatum, hippocampus and amygdale). The early-fetal and late-fetal periods were the vital periods for $7 \mathrm{q} 11.23 \mathrm{CNV}$ proteins to affect human brain development. These results are in agreement with studies showing that GTF2I haplo-insufficient mice exhibit a small brain and neural defects during embryonic development [14, 50]. 
Sanders SJ and colleagues showed that the $7 \mathrm{q} 11.23 \mathrm{CNV}$ is involved in the pathogenesis of autism [28]. We observed that mutations in the proteins within the spatiotemporal 7q11.23 network were significantly enriched in ASD genes and the genes associated with developmental delay. Our results are in agreement with previous studies that discovered the fetal period was crucial for the pathogenesis of ASD [28, 51]. Our study suggests that the hippocampus, amygdale, striatum, and frontal lobe, are crucial regions affected by CNV genes. This result is in accordance with a previous report that showed the amygdala, cortex, and hippocampus to be abnormal in mice exhibiting a heterozygous deletion of 7q11.23 [52]. These results indicate the 7q11.23 CNV plays a significant role in development of the amygdala, cortex, and hippocampus of the human brain.

Our data also suggest that GTF2I is a candidate driver gene within the significant networks. Deurloo MHS and colleagues previously showed that GTF2I plays a pathological role in WBS [34]. Microcephaly and retarded growth were observed in mice that were heterozygous for GTF2I [14]. Importantly, one of the pathways our study suggests as being most likely impacted by the $7 \mathrm{q} 11.23 \mathrm{CNV}$ is DNA repair pathway. We observed that GTF2I and RFC2 interacted with PRKDC, a vital hub partner which possesses the highest radiality value. Through proteomic analyses, we identified that GTF2I interacted with PRKDC. As a significant hub partner, PRKDC encodes the catalytic subunit of DNA-dependent protein kinase and is associated with 

homozygous deletion of PRKDC show increased levels of apoptosis in the neocortex [55]. PRKDC maintains the integrity of the genome and plays a neuroprotective role in the nervous system following DNA damage [55]. A common pathogenic mechanism of microcephalic disorders is defective DNA repair [56]. O'Driscoll M and co-workers previously showed that PRKDC mutations can lead to microcephaly [57]. Our present data further demonstrated that GTF2I interacts with PRKDC to involve in a pathway of DNA-damage repair. Dysregulation of DDR pathway has been shown to be a pivotal cause of neurodevelopmental disease [58]. Based on the assessment of spatiotemporal networks, the interaction between GTF2I and PRKDC was observed within the frontal lobe (R1) and striatum, hippocampus, amygdale (R3) during early-fetal (P1) and late-fetal (P4) periods.

We found that several hub partners involved in DNA-repair pathway. BRCA1 interacts with three CNV proteins, GTF2I, GTF2IRD1, and RFC2. GTF2I interacts with BRCA1 in vivo and improves the transcriptional activation of BRCT [44]. The BRCA1-associated genome surveillance complex is related to the recognition and repair of DNA damage. BRCA1 affects the embryonic development of mouse brains and postnatal mouse brain size $[59,60]$. The deletion of BRCA1 in neural progenitors

323 leads to the disruption of normal differentiation [60]. Pyramidal neurons originating from BRCA1-knockout mice lack the typical radial orientation of apical dendrites 
[59]. GTF2I and RFC2 interacts with RPA, which consists of three subunits: RPA1, RPA2, and RPA3. RPA activates ATR-mediated pathways and is involved in ATR-dependent DDR and cell-cycle arrest [61, 62]. O'Driscoll $M$ and colleagues suggested a causal relationship between dysfunction in ATR signaling and developmental delay. GTF2I and GTF2IRD1 heterozygotes exhibit microcephaly and neural defects $[14,50]$. GTF2I and GTF2IRD1 can interact with HDAC3, ZMYM2, and ZMYM3. HDAC3 mediates the deacetylation of histones and plays an important role in cell survival and cell-cycle progression. ZMYM2 and ZMYM3 are members of the MYB transcription factor family. ZMYM2 involves in DDR pathway and transition of the G1/S phase of the cell cycle [63]. ZMYM3 facilitates DNA repair by regulating BRCA1 localization at damaged chromatin [46]. Our results suggest that GTF2I interacts with these hub proteins and involves in DNA-repair pathway to affect brain development.

\section{Conclusions}

We identified that striatum, hippocampus, and amygdala are crucial regions for establishing connectivity between $7 q 11.23$ proteins and their partners in early and late fetal periods. Our results showed that GTF2I interacted with PRKDC, BRCA1 and other partners to involve in DDR pathway, and demonstrated its crucial role in the early and late fetal stages of brain development. 
Identification of $7 q 11.23$ genes and the human brain transcriptome data collection

Twenty-three genes located on the regions encompassing $\sim 1.4 \mathrm{Mb}$ (chromosome 7 :

72.4-73.4 Mb) [9, 64]. FKBP6 and WBCRS28, were excluded because these two genes are not expressed $\left(\log _{2}\right.$-intensity $\left.<0.4\right)$ in the human brain.(supplementary

table 1). This study utilized region- and time-specific transcriptomic data from the developing human brain; these data were acquired from BrainSpan (www.brainspan.org/) and linked to Gencode v3c genes.RNA-sequencing data from 16 cortical and subcortical structures of 13 developmental stages. To reduce noise, we removed genes with a $\log _{2}$-intensity $<0.4$ in all samples and with a coefficient of variation $<0.07$. Consequently, 15,095 genes were regarded to be expressed in the brain. Biogrid 3.4.161 (www.Biogrid.com) was downloaded in May 2018. Only physical PPIs were reserved. Following the removal of redundant and self-interacting data, 241123 pairs were retained. Physical PPIs were combined with the human brain transcriptome to construct a brain-expressed human interactome $\left(\mathrm{HI}_{\mathrm{BE}}\right)$.

\section{Construction of a spatiotemporal protein network}

Human-brain transcription data were divided by 13 dissection stages from 16 anatomic structures [23]. We defined eight non-overlapping periods by merging the 
by eliminating samples from those that were 40 years-of-age due to their limited size

[27]. According to anatomical and functional similarities, anatomical structures were

divided into four areas (Supplementary Material). Therefore, 31 spatiotemporal protein networks were constructed following the removal of one region from P3 (P3R4) due to a lack of RNA-sequencing data. Genes within the 7q11.23 CNV were mapped to the $\mathrm{HI}_{\mathrm{BE}}$ network to establish a static network. Data exhibiting

371 spatiotemporal expression were incorporated with static PPI networks and the Spearman correlation coefficient was calculated. Interactions were corroborated only

373 if the Spearman correlation coefficient was $>0.5$. Consequently, 31 networks were constructed. Cytoscape software (version 3.7.2; http://www.cytoscape.org/) was used to visualize the network or specific module, and to calculate topological parameters.

\section{Enrichment analyses in three spatiotemporal networks}

One-way analysis of variance (ANOVA) was performed to assess differences between 7q11.23 networks from the same developmental period (P1R1 and P1R3) or from the same anatomical area (P1R3 and P4R3). Topological features were defined for each gene with the $7 \mathrm{q} 11.23 \mathrm{CNV}$ : the ratio of interacting partners unique to one network

381 and the ratio of interacting partners shared by two networks. Significant differences were identified by ANOVA. Genes within specific networks were analyzed by online tools in Metascape. Functional enrichment was investigated in three GO categories:

384 biological process, molecular function, and cellular component. Terms with $\mathrm{P}<0.01$, 385 a minimum count of 3 , and an enrichment factor $>1.5$ (the enrichment factor was 
defined as the ratio of the observed count to the count expected by chance) were collected and grouped into clusters based on their membership similarities. More specifically, P-values were calculated based on the cumulative hypergeometric distribution. The Q-valuewas calculated using the Benjamini-Hochberg correction to account for multiple testing.

De novo mutations were associated with psychiatry disorders according to 19 publications. FMRP genes, ASD risk genes, and developmental-delay genes were obtained as described previously [65]. Differences between the mutations of interacting proteins from 7q11.23 spatiotemporal networks and mutations from 20240 genes were analyzed by Fisher's exact test. P-values were corrected using the Benjamini-Hochberg method.

\section{Cell culture and transfection}

HEK293T cells were cultured in Dulbecco's modified Eagle's supplemented with $10 \%$ fetal bovine serum, $1 \%$ penicillin-streptomycin, and maintained in a humidified incubator at $37^{\circ} \mathrm{C}$ in an atmosphere containing $5 \% \mathrm{CO}_{2}$. For cell transfection, $1.5 \times 10^{6}$ cells were seeded into a $10-\mathrm{cm}$ dish until they reached $80-90 \%$ confluency. Transfections were undertaken using the jetPRIME Transfection Reagent with pCMV6-entry-myc-GTF2I. After 48 h, cells were washed with phosphate-buffered saline, collected, and resuspended in lysis buffer $(20 \mathrm{mM}$ Tris-Cl, $5 \mathrm{mM}$ EDTA, pH 

phenylmethylsulfonyl fluoride $(1 \mathrm{mM})$ and complete protease inhibitor cocktail.

408 Proteins in the supernatant were collected by centrifugation at 13,000 rpm for $15 \mathrm{~min}$ 409 at $4{ }^{\circ} \mathrm{C} ; 5 \%$ of the supernatant was saved so that it could act as an input control. The remaining cell lysates were immunoprecipitated with anti-Myc antibody

411 (Sigma-Aldrich, Saint Louis, MO, USA) or normal mouse IgG (Sigma-Aldrich)

412 rotated for $12 \mathrm{~h}$ at $4^{\circ} \mathrm{C}$. Subsequently, cell lysates were added to $40 \mu \mathrm{L}$ of protein $\mathrm{G}$

413 beads and rotated overnight at $4^{\circ} \mathrm{C}$. Immunocomplexes were washed three times in 414 lysis buffer and boiled with $5 \times$ SDS sample buffer; the supernatant was then collected 415 by centrifugation at $12000 \mathrm{rpm}$ for $1 \mathrm{~min}$ at $4^{\circ} \mathrm{C}$. Supernatants were resolved by $4-20 \%$ 416 polyacrylamide Tris-glycine SDS gels and stained by Coomassie Brilliant Blue. 417 Protein bands were excised (120 kDa and above $270 \mathrm{kDa})$

\section{Peptide preparation and LC-MS/MS}

419 First, gels were de-stained with 50\% (v/v) methanol and vortexed vigorously for 30 $420 \mathrm{~min}$. After de-staining, gel pieces were washed in water for $15 \mathrm{~min}$. Gel pieces were 421 then dehydrated in $100 \%$ acetonitrile for $10 \mathrm{~min}$ and dried in a vacuum centrifuge. 422 The disulfide bonds of proteins were then reduced with dithiothreitol $(10 \mathrm{mM})$ and 423 alkylated with iodoacetamide $(55 \mathrm{mM})$. Next, gel pieces were washed with $50 \%(\mathrm{v} / \mathrm{v})$ 424 acetonitrile, $\mathrm{NH}_{4} \mathrm{HCO}_{3}(25 \mathrm{mM})$ and dehydrated with $100 \%$ acetonitrile. Gel pieces 425 were digested with trypsin in $\mathrm{NH}_{4} \mathrm{HCO}_{3}(25 \mathrm{mM})$. Peptides were extracted with $50 \%$ $426(v / v)$ acetonitrile and 1\% $(v / v)$ trifluoroacetic acid. Free peptides were dried using a 
vacuum centrifuge and separated using a liquid chromatograph (Easy-nLC 1000; Thermo Fisher, Waltham, MA, USA) and introduced into a Q Exactive mass spectrometer (Thermo Fisher). Finally, peptides were analyzed by MASCOT (www.matrixscience.com).

\title{
Proteome analyses
}

Data analyses were undertaken using Proteome Discoverer 1.4 (Thermo Scientific) which incorporates the MASCOT search engine. The Homo sapiens database from Uniprot was downloaded on 15 August 2019 and human protein sequences were searched. Carbamidomethyl was used as the fixed modification, with oxidation as the dynamical modification. The maximum number of missed cleavages considered was two. Immunoprecipitation samples were prepared in three independent experiments. Analyses involved only proteins that were detected by MS at least twice.

\footnotetext{
Abbreviations:

CNVs: Copy number variants; PPI: Protein-protein interaction; DDR: DNA Damaging Response; iPSC: Induced pluripotent stem cell; Co-IP: Co-immunoprecipitation; LC-MS/MS: Liquid chromatography-tandem mass spectrometry; FDR: False-discovery rate; ANOVA: Analysis of variance; GO: Gene ontology; KEGG: Kyoto Encyclopedia of Genes and Genomes; ASD: Autism spectrum disorder; WBS: Williams-Beuren syndrome; FMRP: fragile $\mathrm{X}$ mental retardation protein; IgG: Immunoglobulin G; CBB: Coomassie brilliant blue;
}

\author{
Acknowledgments \\ Not applicable \\ Conflict of interest
}




\section{Author contributions}

G.-N.L designed the experiments, interpreted the results, revised and approved the final version of the manuscipt. Liang Chen designed the experiments, performed data analysis, conducted the major experiments, interpreted the results and drafted the manuscript. W.-X.C conducts part of experiments. W.-C.S and W.Q participated in data collection. W.-D.W revised the manuscript.

\section{Funding}

This work was supported by grants from National Natural Science Foundation of China (No. 81671328, 81971292); Program for Professor of Special Appointment (Eastern Scholar) at Shanghai Institutions of Higher Learning (No. 1610000043); Innovation Research Plan supported by Shanghai Municipal Education Commission (ZXWF082101).

\section{Availability of data and materials}

The datasets used and/or analysed during the current study are available from the corresponding author on reasonable request.

\section{Ethics approval and consent to participate}

Not applicable

472

\section{Consent for publication}

474

Not applicable

475

\section{Author details}

${ }^{1}$ Shanghai Mental Health Center, Shanghai Jiao Tong University School of Medicine, School of

\section{References}

1. Freeman JL, Perry GH, Feuk L, Redon R, McCarroll SA, Altshuler DM, et al. Copy number variation: new insights in genome diversity. Genome Res. 2006;16(8):949-61.

2. Myocardial Infarction Genetics $C$, Kathiresan S, Voight BF, Purcell S, Musunuru K, Ardissino D, et al. Genome-wide association of early-onset myocardial infarction with single nucleotide polymorphisms and copy number variants. Nat Genet. 2009;41(3):334-41. variation reveals ubiquitin and neuronal genes. Nature. 2009;459(7246):569-73. 
4. Yang Y, Chung EK, Wu YL, Savelli SL, Nagaraja HN, Zhou B, et al. Gene copy-number variation and associated polymorphisms of complement component $\mathrm{C} 4$ in human systemic lupus erythematosus (SLE): low copy number is a risk factor for and high copy number is a protective factor against SLE susceptibility in European Americans. Am J Hum Genet. 2007;80(6):1037-54.

5. Thygesen JH, Wolfe K, McQuillin A, Vinas-Jornet M, Baena N, Brison N, et al. Neurodevelopmental risk copy number variants in adults with intellectual disabilities and comorbid psychiatric disorders. Br J Psychiatry. 2018;212(5):287-94.

6. Mulle JG, Pulver AE, McGrath JA, Wolyniec PS, Dodd AF, Cutler DJ, et al. Reciprocal duplication of the Williams-Beuren syndrome deletion on chromosome 7q11.23 is associated with schizophrenia. Biol Psychiatry. 2014;75(5):371-7.

7. Depienne C, Héron D, Betancur C, Benyahia B, Trouillard O, Bouteiller D, et al. Autism, language delay and mental retardation in a patient with $7 q 11$ duplication. Journal of medical genetics. 2007;44(7):452-8.

8. Castiglia L, Husain RA, Marquardt I, Fink C, Liehr T, Serino D, et al. 7q11.23 microduplication syndrome: neurophysiological and neuroradiological insights into a rare chromosomal disorder. J Intellect Disabil Res. 2018;62(5):359-70.

9. Sanders SJ, Ercan-Sencicek AG, Hus V, Luo R, Murtha MT, Moreno-De-Luca D, et al. Multiple recurrent de novo CNVs, including duplications of the $7 q 11.23$ Williams syndrome region, are strongly associated with autism. Neuron. 2011;70(5):863-85.

10. Berg JS, Brunetti-Pierri N, Peters SU, Kang SH, Fong CT, Salamone J, et al. Speech delay and autism spectrum behaviors are frequently associated with duplication of the 7q11.23 Williams-Beuren syndrome region. Genet Med. 2007;9(7):427-41.

11. Faravelli F, D'Arrigo S, Bagnasco I, Selicorni A, D'Incerti L, Riva D, et al. Oligoyric microcephaly in a child with Williams syndrome. Am J Med Genet A. 2003;117A(2):169-71.

12. Van der Aa N, Rooms L, Vandeweyer G, van den Ende J, Reyniers E, Fichera M, et al. Fourteen new cases contribute to the characterization of the 7q11.23 microduplication syndrome. Eur J Med Genet. 2009;52(2-3):94-100.

13. Adamo A, Atashpaz S, Germain PL, Zanella M, D'Agostino G, Albertin V, et al. 7q11.23 dosage-dependent dysregulation in human pluripotent stem cells affects transcriptional programs in disease-relevant lineages. Nat Genet. 2015;47(2):132-41.

14. Enkhmandakh B, Makeyev AV, Erdenechimeg L, Ruddle FH, Chimge N-O, Tussie-Luna MI, et al. Essential functions of the Williams-Beuren syndrome-associated TFII-I genes in embryonic development. Proceedings of the National Academy of Sciences. 2009;106(1):181-6.

15. Noskov VN, Araki H, Sugino A. The RFC2 gene, encoding the third-largest subunit of the replication factor $\mathrm{C}$ complex, is required for an S-phase checkpoint in Saccharomyces cerevisiae. Molecular and Cellular Biology. 1998;18(8):4914-23.

16. Zou L, Cortez D, Elledge SJ. Regulation of ATR substrate selection by Rad17-dependent loading of Rad9 complexes onto chromatin. Genes Dev. 2002;16(2):198-208.

17. Zou L, Liu D, Elledge SJ. Replication protein A-mediated recruitment and activation of Rad17 complexes. Proceedings of the National Academy of Sciences. 2003;100(24):13827-32.

18. O'Driscoll M, Dobyns WB, van Hagen JM, Jeggo PA. Cellular and clinical impact of haploinsufficiency for genes involved in ATR signaling. Am J Hum Genet. 2007;81(1):77-86.

19. Zhou J, Lemos B, Dopman EB, Hartl DL. Copy-number variation: the balance between gene dosage 
and expression in Drosophila melanogaster. Genome Biol Evol. 2011;3:1014-24.

20. Orozco LD, Cokus SJ, Ghazalpour A, Ingram-Drake L, Wang S, van Nas A, et al. Copy number variation influences gene expression and metabolic traits in mice. Hum Mol Genet. 2009;18(21):4118-29.

21. Bassett AS, Lowther C, Merico D, Costain G, Chow EWC, van Amelsvoort T, et al. Rare Genome-Wide Copy Number Variation and Expression of Schizophrenia in 22q11.2 Deletion Syndrome. Am J Psychiatry. 2017;174(11):1054-63.

22. Khaitovich P, Muetzel B, She X, Lachmann M, Hellmann I, Dietzsch J, et al. Regional patterns of gene expression in human and chimpanzee brains. Genome Res. 2004;14(8):1462-73.

23. Kang HJ, Kawasawa YI, Cheng F, Zhu Y, Xu X, Li M, et al. Spatio-temporal transcriptome of the human brain. Nature. 2011;478(7370):483-9.

24. Itoh J, Sato Y, Sato Y, Hibara K, Shimizu-Sato S, Kobayashi H, et al. Genome-wide analysis of spatiotemporal gene expression patterns during early embryogenesis in rice. Development. 2016;143(7):1217-27.

25. Grennan KS, Chen C, Gershon ES, Liu C. Molecular network analysis enhances understanding of the biology of mental disorders. Bioessays. 2014;36(6):606-16.

26. Tanay A, Sharan R, Kupiec M, Shamir R. Revealing modularity and organization in the yeast molecular network by integrated analysis of highly heterogeneous genomewide data. Proceedings of the National Academy of Sciences. 2004;101(9):2981-6.

27. Lin GN, Corominas R, Lemmens I, Yang X, Tavernier J, Hill DE, et al. Spatiotemporal 16p11.2 protein network implicates cortical late mid-fetal brain development and KCTD13-Cul3-RhoA pathway in psychiatric diseases. Neuron. 2015;85(4):742-54.

28. Willsey AJ, Sanders SJ, Li M, Dong S, Tebbenkamp AT, Muhle RA, et al. Coexpression networks implicate human midfetal deep cortical projection neurons in the pathogenesis of autism. Cell. 2013;155(5):997-1007.

29. Cheng L, Leung KS. Quantification of non-coding RNA target localization diversity and its application in cancers. J Mol Cell Biol. 2018;10(2):130-8.

30. Cheng L, Fan K, Huang Y, Wang D, Leung KS. Full Characterization of Localization Diversity in the Human Protein Interactome. J Proteome Res. 2017;16(8):3019-29.

31. Ge H, Liu Z, Church GM, Vidal M. Correlation between transcriptome and interactome mapping data from Saccharomyces cerevisiae. Nat Genet. 2001;29(4):482-6.

32. Zhou Y, Zhou B, Pache L, Chang M, Khodabakhshi AH, Tanaseichuk O, et al. Metascape provides a biologist-oriented resource for the analysis of systems-level datasets. Nat Commun. 2019;10(1):1523.

33. Deurloo MHS, Turlova E, Chen WL, Lin YW, Tam E, Tassew NG, et al. Transcription Factor 21 Regulates Neuronal Development via TRPC3 in 7q11.23 Disorder Models. Mol Neurobiol. 2019;56(5):3313-25.

34. Barak B, Zhang Z, Liu Y, Nir A, Trangle SS, Ennis M, et al. Neuronal deletion of Gtf2i, associated with Williams syndrome, causes behavioral and myelin alterations rescuable by a remyelinating drug. Nat Neurosci. 2019;22(5):700-8.

35. Dutra RL, Pieri Pde C, Teixeira AC, Honjo RS, Bertola DR, Kim CA. Detection of deletions at 7q11.23 in Williams-Beuren syndrome by polymorphic markers. Clinics (Sao Paulo). 2011;66(6):959-64.

36. Antonell A, Del Campo M, Magano LF, Kaufmann L, de la Iglesia JM, Gallastegui F, et al. Partial 
7q11.23 deletions further implicate GTF2I and GTF2IRD1 as the main genes responsible for the Williams-Beuren syndrome neurocognitive profile. J Med Genet. 2010;47(5):312-20.

37. Sakurai T, Dorr NP, Takahashi N, McInnes LA, Elder GA, Buxbaum JD. Haploinsufficiency of Gtf2i, a gene deleted in Williams Syndrome, leads to increases in social interactions. Autism Res. 2011;4(1):28-39.

38. Mervis CB, Dida J, Lam E, Crawford-Zelli NA, Young EJ, Henderson DR, et al. Duplication of GTF2I results in separation anxiety in mice and humans. Am J Hum Genet. 2012;90(6):1064-70.

39. Smith GC, Jackson SP. The DNA-dependent protein kinase. Genes \& development. 1999;13(8):916-34.

40. Anderson CW, Dunn JJ, Freimuth PI, Galloway AM, Joan Allalunis-Turner M. Frameshift mutation in PRKDC, the gene for DNA-PKCs, in the DNA repair-defective, human, glioma-derived cell line M059J. Radiation research. 2001;156(1):2-9.

41. Felgentreff K, Du L, Weinacht KG, Dobbs K, Bartish M, Giliani S, et al. Differential role of nonhomologous end joining factors in the generation, DNA damage response, and myeloid differentiation of human induced pluripotent stem cells. Proc Natl Acad Sci U S A. 2014;111(24):8889-94.

42. Wei L, Lan L, Hong Z, Yasui A, Ishioka C, Chiba N. Rapid recruitment of BRCA1 to DNA double-strand breaks is dependent on its association with Ku80. Mol Cell Biol. 2008;28(24):7380-93.

43. Cortez D, Wang Y, Qin J, Elledge SJ. Requirement of ATM-dependent phosphorylation of brca1 in the DNA damage response to double-strand breaks. Science. 1999;286(5442):1162-6.

44. Tanikawa M, Wada-Hiraike O, Nakagawa S, Shirane A, Hiraike H, Koyama S, et al. Multifunctional transcription factor TFIII is an activator of BRCA1 function. Br J Cancer. 2011;104(8):1349-55.

45. Aguilar-Martinez E, Chen X, Webber A, Mould AP, Seifert A, Hay RT, et al. Screen for multi-SUMO-binding proteins reveals a multi-SIM-binding mechanism for recruitment of the transcriptional regulator ZMYM2 to chromatin. Proc Natl Acad Sci U S A. 2015;112(35):E4854-63.

46. Leung JW, Makharashvili N, Agarwal P, Chiu LY, Pourpre R, Cammarata MB, et al. ZMYM3 regulates BRCA1 localization at damaged chromatin to promote DNA repair. Genes Dev. 2017;31(3):260-74.

47. Long J, Fang WY, Chang L, Gao WH, Shen Y, Jia MY, et al. Targeting HDAC3, a new partner protein of AKT in the reversal of chemoresistance in acute myeloid leukemia via DNA damage response. Leukemia. 2017;31(12):2761-70.

48. Gratten J, Wray NR, Peyrot WJ, McGrath JJ, Visscher PM, Goddard ME. Risk of psychiatric illness from advanced paternal age is not predominantly from de novo mutations. Nat Genet. 2016;48(7):718-24.

49. Fromer M, Pocklington AJ, Kavanagh DH, Williams HJ, Dwyer S, Gormley $P$, et al. De novo mutations in schizophrenia implicate synaptic networks. Nature. 2014;506(7487):179-84.

50. van Hagen JM, van der Geest JN, van der Giessen RS, Lagers-van Haselen GC, Eussen HJ, Gille JJ, et al. Contribution of CYLN2 and GTF2IRD1 to neurological and cognitive symptoms in Williams Syndrome. Neurobiol Dis. 2007;26(1):112-24.

51. Courchesne E, Mouton PR, Calhoun ME, Semendeferi K, Ahrens-Barbeau C, Hallet MJ, et al. Neuron number and size in prefrontal cortex of children with autism. Jama. 2011;306(18):2001-10.

52. Segura-Puimedon M, Sahun I, Velot E, Dubus P, Borralleras C, Rodrigues AJ, et al. Heterozygous deletion of the Williams-Beuren syndrome critical interval in mice recapitulates most features of 
the human disorder. Hum Mol Genet. 2014;23(24):6481-94.

53. Lu H, Saha J, Beckmann PJ, Hendrickson EA, Davis AJ. DNA-PKcs promotes chromatin decondensation to facilitate initiation of the DNA damage response. Nucleic Acids Res. 2019;47(18):9467-79.

54. Jiang W, Crowe JL, Liu X, Nakajima S, Wang Y, Li C, et al. Differential phosphorylation of DNA-PKCS regulates the interplay between end-processing and end-ligation during nonhomologous end-joining. Mol Cell. 2015;58(1):172-85.

55. Enriquez-Rios V, Dumitrache LC, Downing SM, Li Y, Brown EJ, Russell HR, et al. DNA-PKcs, ATM, and ATR Interplay Maintains Genome Integrity during Neurogenesis. J Neurosci. 2017;37(4):893-905.

56. O'Driscoll M, Jackson AP, Jeggo PA. Microcephalin: a causal link between impaired damage response signalling and microcephaly. Cell Cycle. 2006;5(20):2339-44.

57. Woodbine L, Neal JA, Sasi NK, Shimada M, Deem K, Coleman H, et al. PRKDC mutations in a SCID patient with profound neurological abnormalities. J Clin Invest. 2013;123(7):2969-80.

58. Lee Y, Choi I, Kim J, Kim K. DNA damage to human genetic disorders with neurodevelopmental defects. Journal of Genetic Medicine. 2016;13(1):1-13.

59. Pao GM, Zhu Q, Perez-Garcia CG, Chou SJ, Suh H, Gage FH, et al. Role of BRCA1 in brain development. Proc Natl Acad Sci U S A. 2014;111(13):E1240-8.

60. Pulvers JN, Huttner WB. Brca1 is required for embryonic development of the mouse cerebral cortex to normal size by preventing apoptosis of early neural progenitors. Development. 2009;136(11):1859-68.

61. Choi JH, Lindsey-Boltz LA, Kemp M, Mason AC, Wold MS, Sancar A. Reconstitution of RPA-covered single-stranded DNA-activated ATR-Chk1 signaling. Proc Natl Acad Sci $U S A$. 2010;107(31):13660-5.

62. Borgstahl GE, Brader K, Mosel A, Liu S, Kremmer E, Goettsch KA, et al. Interplay of DNA damage and cell cycle signaling at the level of human replication protein A. DNA Repair (Amst). 2014;21:12-23.

63. Cibis H, Biyanee A, Dorner W, Mootz HD, Klempnauer KH. Characterization of the zinc finger proteins ZMYM2 and ZMYM4 as novel B-MYB binding proteins. Sci Rep. 2020;10(1):8390.

64. Cooper GM, Coe BP, Girirajan S, Rosenfeld JA, Vu TH, Baker C, et al. A copy number variation morbidity map of developmental delay. Nat Genet. 2011;43(9):838-46.

65. Corominas R, Yang X, Lin GN, Kang S, Shen Y, Ghamsari L, et al. Protein interaction network of alternatively spliced isoforms from brain links genetic risk factors for autism. Nat Commun. 2014;5:3650. 

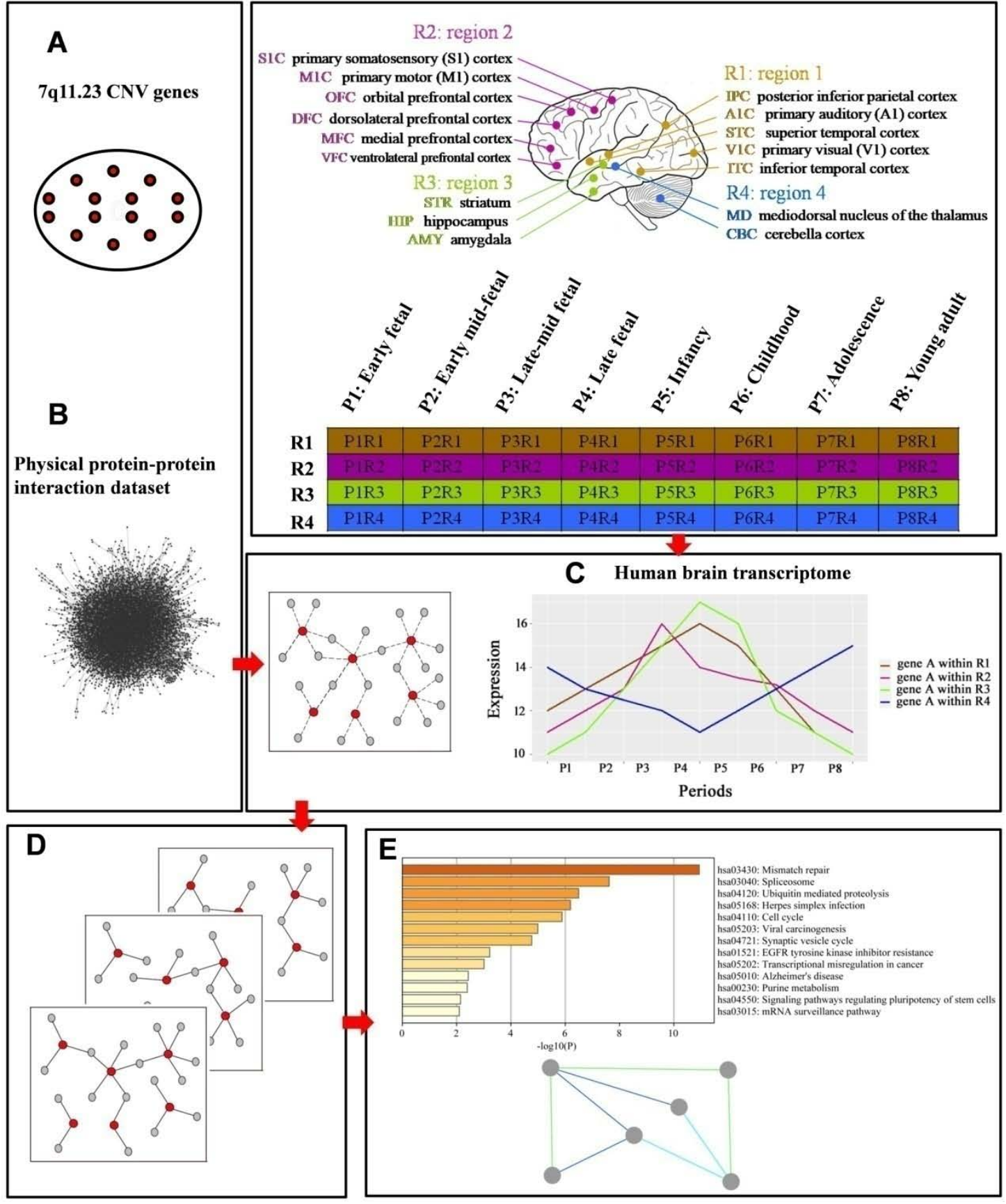

Fig. 1 A flow-chart shows the plan of work involved in this research study. (A) Twenty-three 7q11.23 CNV genes expressed in the brain were identified. (B) Physical protein-protein interaction dataset combined with $7 \mathrm{q} 11.23 \mathrm{CNV}$ genes to construct CNV protein-protein interactions (PPIs). (C) 7q11.23 CNV PPIs combined with the Human brain transcriptome dataset. (D) 7q11.23 spatiotemporal co-expression PPIs network was established. (E) Functional enrichment analysis and functional module analysis were performed. 


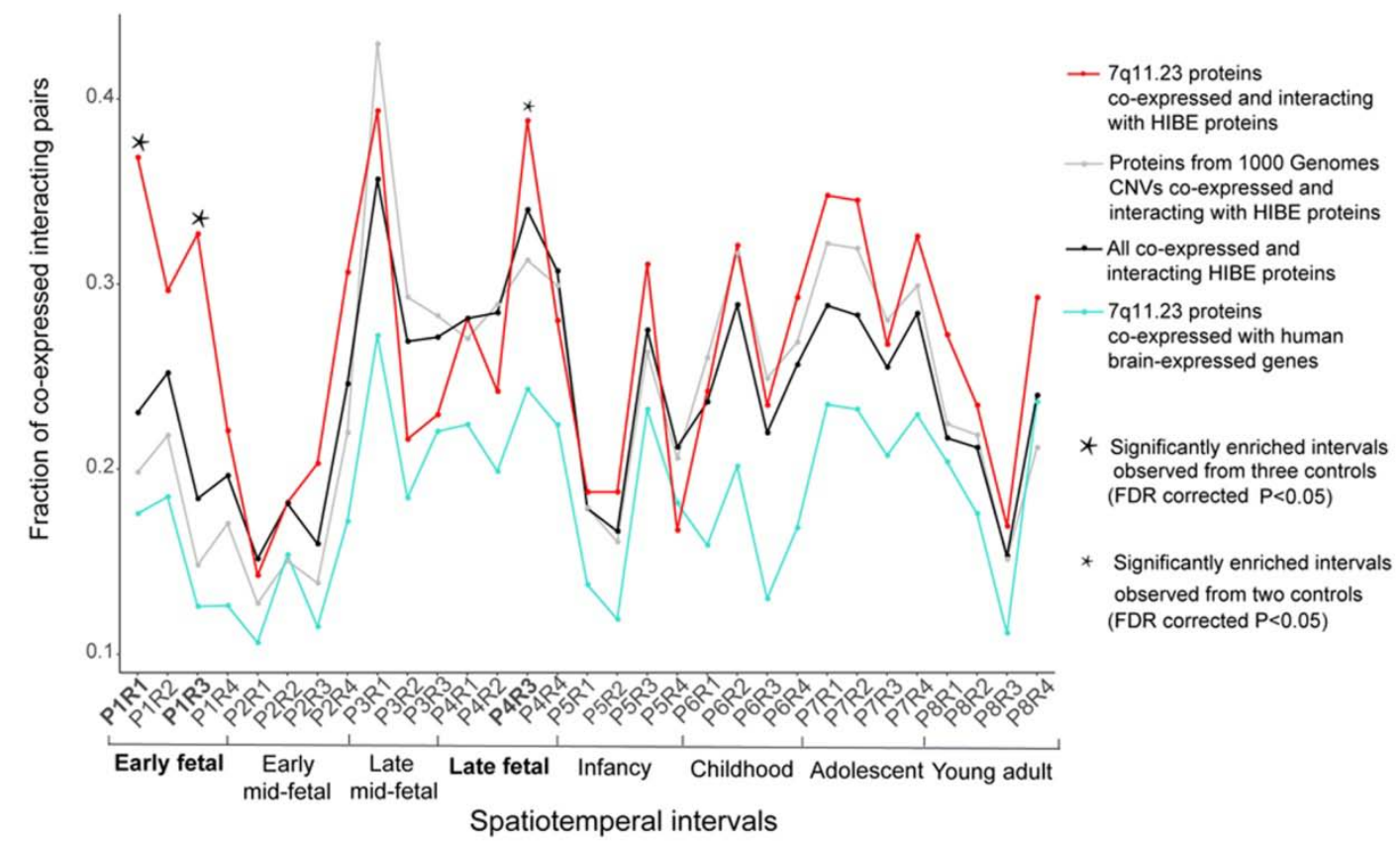

Fig. 2 The 7q11.23 co-expressed interacting protein pairs are significantly enriched in three spatiotemporal intervals. The fractions of protein pairs from 7q11.23 CNV co-expressed and interacting with HIBE proteins (red line), all co-expressed and interacting HIBE proteins (black line), proteins from 1000 Genome Project CNVs co-expressed and interacting with HIBE proteins (dark gray line), and 7q11.23 CNV proteins co-expressed with all brain-expressed human genes (aquamarine line). Thirty-one spatiotemporal intervals of brain development are shown on the x-axis. 7q11.23 co-expressed interacting protein pairs are significantly enriched in spatiotemporal intervals (indicated by star symbol) compared with control networks. The statistical enrichment was calculated using Fisher's exact test, and $p$ values were FDR-corrected for multiple comparisons. 


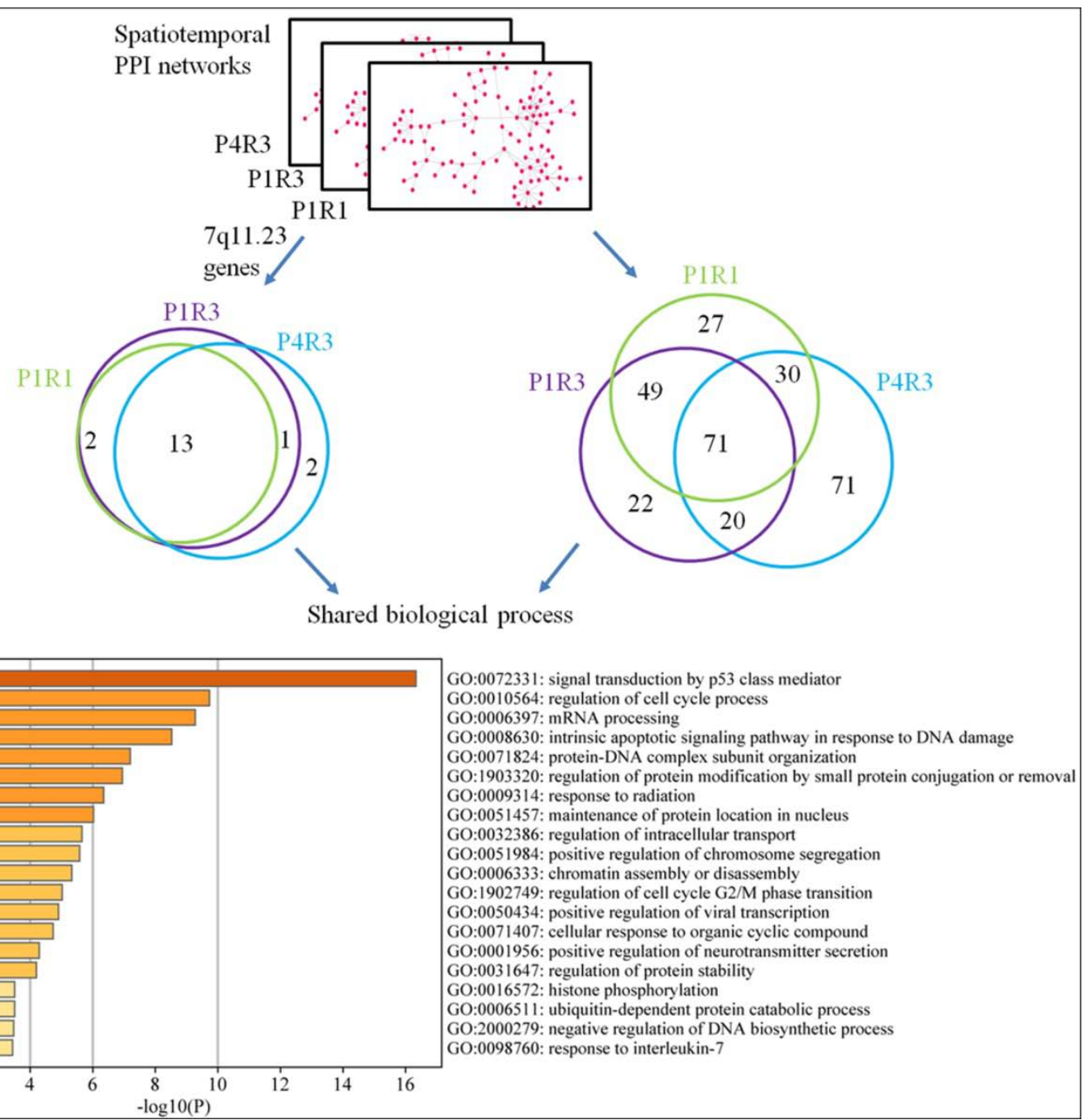

687 Fig. 3 Functional convergence of the 7q11.23 spatiotemporal networks. The overlap of 7q11.23 genes (left Venn diagram) and their co-expressed interacting partners (right Venn diagram) across three significant spatiotemporal intervals. Top 20 significant enriched biological process GO terms of shared proteins are showed. 


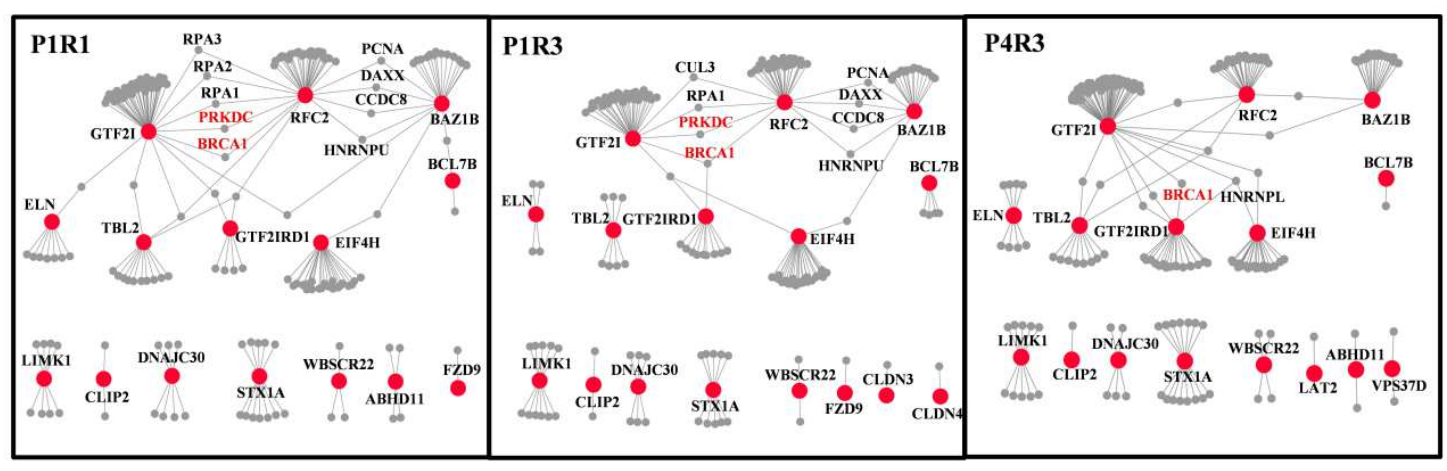

\begin{tabular}{|c|c|c|c|c|c|}
\hline ANOVA tests & sum of squares & df & mean square & $\mathbf{F}$ & P-values \\
\hline $\mathrm{P} 1 \mathrm{R} 1$ and P1R3 & 0.111 & 1 & 0.1106 & 0.904 & 0.349 \\
\hline $\mathrm{P} 1 \mathrm{R} 3$ and P4R3 & 3.686 & 1 & 3.686 & 105.7 & $2.95 \times 10^{-12 * * *}$ \\
\hline
\end{tabular}

Fig. 4 Difference between the 7q11.23 spatiotemporal networks. Comparison of spatiotemporal networks across different brain regions within the same developmental period (P1R1 and P1R3) and cross different development periods within the same brain region (P1R3 and P4R3). 7q11.23 genes are shown as red nodes, their co-expressed interacting partners as gray node, and the PPIs between co-expressed genes at a particular developmental period are shown as gray edges. The nodes that lost all edges were removed from the corresponding networks. Significant differences are observed across developmental periods but not across brain regions (ANOVA statistics shown below the graphs). 


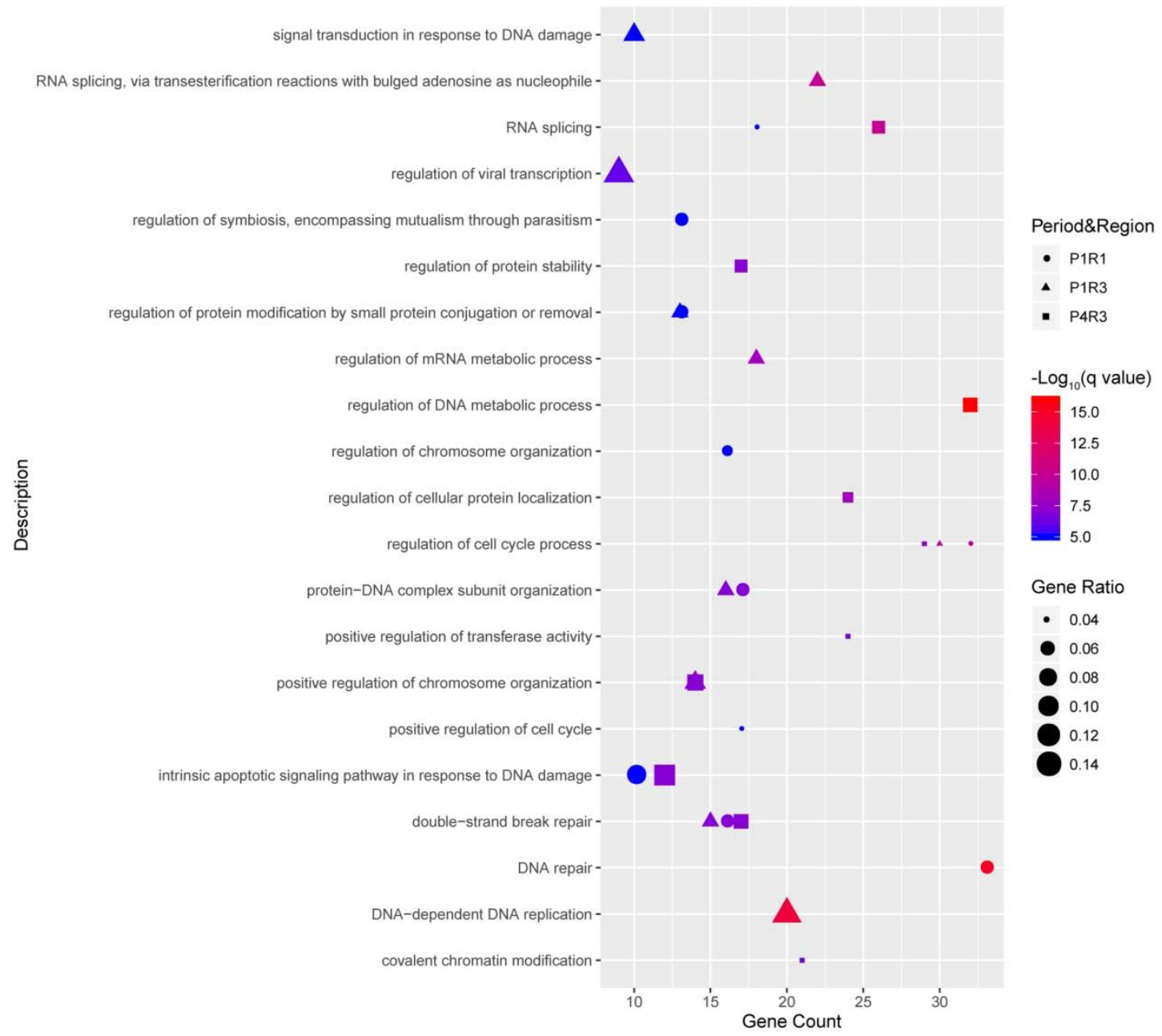

Fig. 5 Functional analyses of proteins within three significant intervals, P1R1, 

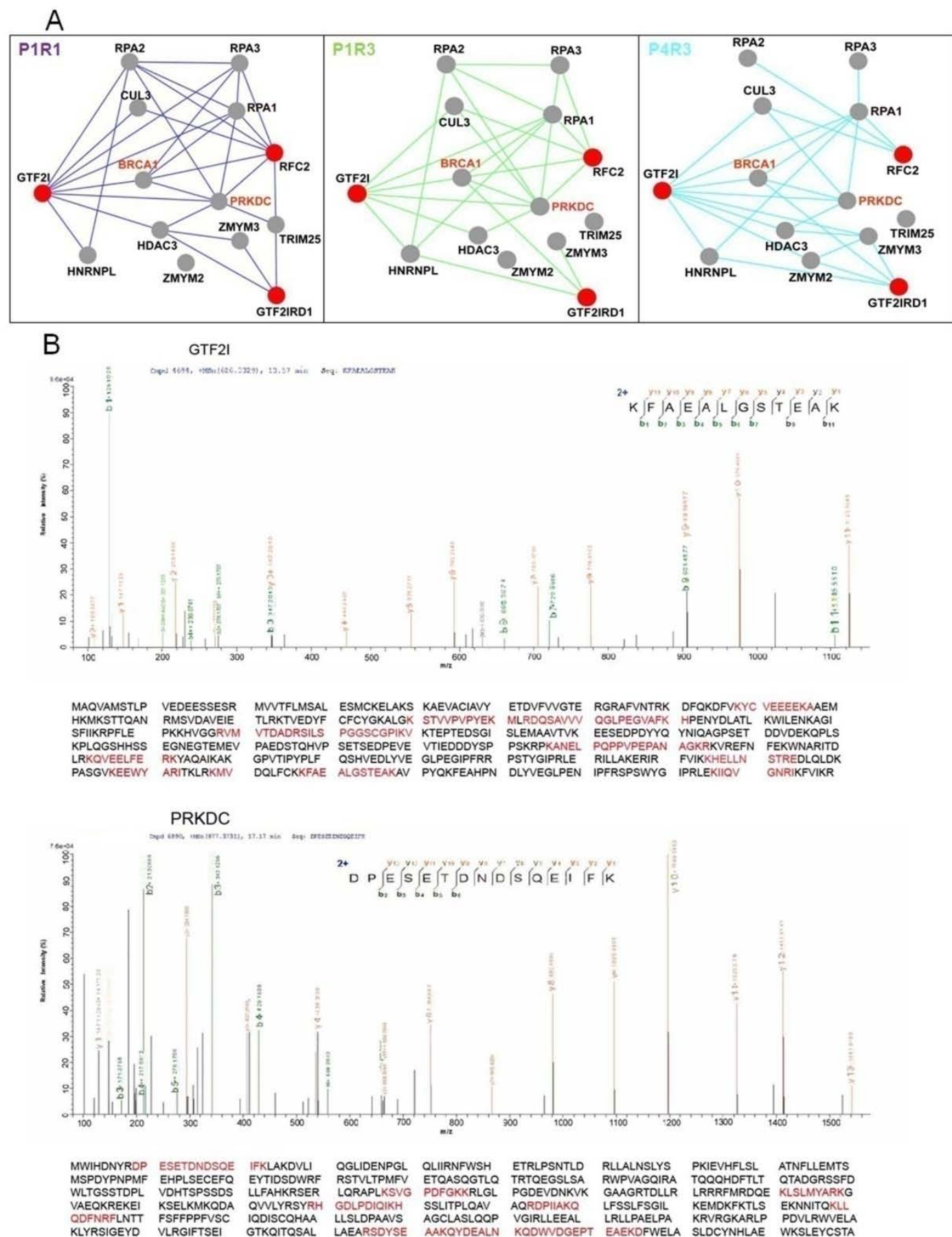

Fig. 6 Spatiotemporal networks implicate GTF2I-PRKDC-DDR pathway and proteomic investigation of interaction between GTF2I and PRKDC. (A) Dynamic spatiotemporal networks of the GTF2I, GTF2IRD1, and RFC2 interacted with their hub partners. 7q11.23 genes are shown as red nodes, their co-expressed hub partners as gray node, and the PPIs between co-expressed genes at a particular developmental period are shown as gray edges. The nodes that lost all edges were removed from the 
740 corresponding networks, and the PPIs between co-expressed genes at a particular

741 developmental period are showed as colored edges (P1R1, blueviolet; P1R3, green;

742 P4R3, turquoises). (B) GTF2I and PRKDC were identified and the amino acids

743 highlighted are peptides identified by immunoprecipitation (IP) and LC-MS/MS.

744

745

746

747

748

749

750

751

752

753

754

755

756

757

758 
Table S1. Genes of 7q11.23 Copy number variation (CNV) region

\begin{tabular}{|c|c|c|c|c|}
\hline Gene ID & $\begin{array}{c}\text { Gene } \\
\text { symbole }\end{array}$ & Official full name & position (hg38) & size \\
\hline 8468 & FKBP6 & FKBP prolyl isomerase 6 & $\operatorname{chr} 7: 73,328,161-73,358,625$ & 30,465 \\
\hline 8326 & FZD9 & frizzled class receptor 9 & chr7:73,433,778-73,436,120 & 2,343 \\
\hline 9031 & BAZ1B & $\begin{array}{l}\text { bromodomain adjacent to Zinc finger } \\
\text { domain 1B }\end{array}$ & $\operatorname{chr} 7: 73,440,406-73,522,293$ & 81,888 \\
\hline 9275 & BCL7B & B-cell lymphoma 7 & chr7:73,536,356-73,557,690 & 21,335 \\
\hline 26608 & TBL2 & transducin-beta like 2 & chr7:73,567,537-73,578,579 & 11,043 \\
\hline 51085 & MLXIPL & MLX interacting protein like & chr7:73,593,194-73,624,540 & 31,347 \\
\hline 155382 & VPS37D & VPS37D subunit of ESCRT-I & chr7:73,667,831-73,672,110 & 4,280 \\
\hline 84277 & DNAJC30 & $\begin{array}{l}\text { DnaJ heat shock protein family member } \\
\text { C30 }\end{array}$ & $\operatorname{chr} 7: 73,680,918-73,683,453$ & 2,536 \\
\hline 114049 & WBSCR22 & $\begin{array}{c}\text { Williams-Beuren syndrome chromosome } \\
\text { region } 22\end{array}$ & $\operatorname{chr} 7: 73,683,568-73,698,212$ & 14,645 \\
\hline 6804 & STX1A & syntaxin $1 \mathrm{~A}$ & chr7:73,700,827-73,719,631 & 18,805 \\
\hline 83451 & ABHD11 & abhydrolase domain containing 11 & chr7:73,736,094-73,738,867 & 2,774 \\
\hline 1365 & CLDN3 & claudin 3 & chr7:73,768,997-73,770,270 & 1,274 \\
\hline 1364 & CLDN4 & claudin 4 & chr7:73,827,744-73,832,684 & 4,941 \\
\hline 155368 & WBSCR27 & methyltransferase like 27 & chr7:73,834,590-73,842,516 & 7,927 \\
\hline 135886 & WBSCR28 & transmembrane protein 270 & chr7:73,861,159-73,865,890 & 4,732 \\
\hline 2006 & ELN & elastin & chr7:74,027,789-74,069,907 & 42,119 \\
\hline 3984 & LIMK1 & LIM domain kinase 1 & chr7:74,082,933-74,122,525 & 39,593 \\
\hline 7458 & EIF4H & eukaryotic translation initiation factor $4 \mathrm{H}$ & chr7:74,174,245-74,197,101 & 22,857 \\
\hline 7462 & LAT2 & $\begin{array}{c}\text { linker for activation of } \mathrm{T} \text { cells family } \\
\text { member } 2\end{array}$ & $\operatorname{chr} 7: 74,209,396-74,229,834$ & 20,439 \\
\hline 5982 & RFC2 & replication factor $\mathrm{C}$, subunit 2 & $\operatorname{chr} 7: 74,231,499-74,254,389$ & 22,891 \\
\hline 7461 & CLIP2 & $\begin{array}{l}\text { CAP-Gly domain containing linker } \\
\text { protein } 2\end{array}$ & $\operatorname{chr} 7: 74,289,475-74,405,943$ & 116,469 \\
\hline 9569 & GTF2IRD1 & GTF2I repeat domain containing 1 & chr7:74,453,970-74,602,604 & 148,635 \\
\hline 2969 & GTF2I & general transcription factor II-I & chr7:74,650,231-74,760,692 & 110,462 \\
\hline
\end{tabular}


Table S2. Developmental brain period from the BrainSpan related to Figure 1

\begin{tabular}{|c|c|c|c|}
\hline stage & Description & Age & Developmental period \\
\hline $\begin{array}{l}1 \\
2\end{array}$ & $\begin{array}{l}\text { Early fetal } \\
\text { Early fetal }\end{array}$ & $\begin{array}{c}\text { 8-9 PCW } \\
\text { 10-12 PCW }\end{array}$ & $\mathrm{P} 1$ \\
\hline $\begin{array}{l}3 \\
4\end{array}$ & $\begin{array}{l}\text { Early mid-fetal } \\
\text { Early mid-fetal }\end{array}$ & $\begin{array}{l}\text { 13-15 PCW } \\
16-18 \text { PCW }\end{array}$ & $\mathrm{P} 2$ \\
\hline 5 & Late mid-fetal & 19-23 PCW & P3 \\
\hline 6 & Late fetal & 24-37 PCW & $\mathrm{P} 4$ \\
\hline $\begin{array}{l}7 \\
8\end{array}$ & $\begin{array}{l}\text { Early infancy } \\
\text { Late infancy }\end{array}$ & $\begin{array}{c}0-5 \mathrm{M} \\
6-11 \mathrm{M}\end{array}$ & P5 \\
\hline $\begin{array}{c}9 \\
10\end{array}$ & $\begin{array}{l}\text { Early childood } \\
\text { late childhood }\end{array}$ & $\begin{array}{c}1-5 \mathrm{Yr} \\
6-11 \mathrm{Yr}\end{array}$ & P6 \\
\hline 11 & Adolescence & $12-19 \mathrm{Yr}$ & $\mathrm{P} 7$ \\
\hline 12 & Young adulthood & $20-40 \mathrm{Yr}$ & P8 \\
\hline
\end{tabular}



from P1R3 and P4R3 networks.

Interaction patterns of $7 \mathrm{q} 11.23 \mathrm{CNV}$ proteins across networks from different development periods.(P1:early fetal; P4: early mid-fetal) of the same brain region (R3: hippocampus, amygdala and striatum) and the results of the ANOVA test related to Fig 4. Bold font indicates the p-value from the ANOVA test (p-value < 0.05)

\begin{tabular}{|c|c|c|c|c|c|c|}
\hline \multicolumn{2}{|c|}{ CNV genes } & \multicolumn{2}{|c|}{ Ineracting } & \multicolumn{3}{|c|}{ partners in P1R3 and P4R3 } \\
\hline \multirow{2}{*}{$\begin{array}{l}\text { Entrez } \\
\text { gene ID }\end{array}$} & \multirow{2}{*}{$\begin{array}{l}\text { Official } \\
\text { symbol }\end{array}$} & \multirow{2}{*}{$\begin{array}{l}\text { Total } \\
\text { partners }\end{array}$} & \multicolumn{2}{|c|}{ unique to 1 network } & \multicolumn{2}{|c|}{$\begin{array}{r}\text { shared } \\
\text { by } 2\end{array}$} \\
\hline & & & count & Freq & count & Freq \\
\hline 8326 & FZD9 & 1 & 1 & 1.0000 & 0 & 0.0000 \\
\hline 9031 & BAZ1B & 27 & 14 & 0.5185 & 13 & 0.4815 \\
\hline 9275 & BCL7B & 5 & 5 & 1.0000 & 0 & 0.0000 \\
\hline 26608 & TBL2 & 16 & 14 & 0.8750 & 2 & 0.1250 \\
\hline 155382 & VPS37D & 2 & 2 & 1.0000 & 0 & 0.0000 \\
\hline 84277 & DNAJC30 & 8 & 5 & 0.6250 & 3 & 0.3750 \\
\hline 114049 & WBSCR22 & 5 & 4 & 0.8000 & 1 & 0.2000 \\
\hline 6804 & STX1A & 19 & 13 & 0.6842 & 6 & 0.3158 \\
\hline 83451 & ABHD11 & 2 & 2 & 1.0000 & 0 & 0.0000 \\
\hline 1365 & CLDN3 & 1 & 1 & 1.0000 & 0 & 0.0000 \\
\hline 1364 & CLDN4 & 1 & 1 & 1.0000 & 0 & 0.0000 \\
\hline 2006 & ELN & 9 & 6 & 0.6667 & 3 & 0.3333 \\
\hline 3984 & LIMK1 & 18 & 15 & 0.8333 & 3 & 0.1667 \\
\hline 7458 & EIF4H & 34 & 21 & 0.6176 & 13 & 0.3824 \\
\hline 7462 & LAT2 & 1 & 1 & 1.0000 & 0 & 0.0000 \\
\hline 5982 & RFC2 & 45 & 30 & 0.6667 & 15 & 0.3333 \\
\hline 7461 & CLIP2 & 3 & 3 & 1.0000 & 0 & 0.0000 \\
\hline 9569 & GTF2IRD1 & 22 & 13 & 0.5909 & 9 & 0.4091 \\
\hline 2969 & GTF2I & 63 & 34 & 0.5397 & 29 & 0.4603 \\
\hline
\end{tabular}

ANOVA Test

Summary

\begin{tabular}{|ccccc|}
\hline $\begin{array}{c}\text { Groups } \\
\text { Frequency of } \\
\text { interactors }\end{array}$ & Count & Sum & Average & Variance \\
\hline Unique to 1 network & 19 & 15.418 & 0.811 & 0.0349 \\
Shared by 2 network & 19 & 3.582 & 0.189 & 0.0349 \\
\hline
\end{tabular}


Result

\begin{tabular}{|cccccc|}
\hline $\begin{array}{c}\text { Source of } \\
\text { variation }\end{array}$ & SS & df & MS & F & p-value \\
\hline Between Groups & 3.686 & 1 & 3.686 & 105.7 & $2.95 \times 10^{-12} * * *$ \\
Within Groups & 1.256 & 36 & 0.035 & & \\
Total & 4.942 & 37 & & & \\
\hline
\end{tabular}

792

Table S4. Results of ANVOVA test for interaction patterns of proteins from P1R1 and P1R3 networks.

Interaction patterns of $16 \mathrm{p} 11.2 \mathrm{CNV}$ proteins across networks from different brain regions (R1: parietal, temporal and occipital cortex; R3:hippocampus, amygdala and striatum) of the same developmental period (P1:early fetal;) and the results of the ANOVA test related to Fig 4. Bold font indicates the p-value from the ANOVA test

801 (Not significant).

\begin{tabular}{|c|c|c|c|c|c|c|}
\hline \multicolumn{2}{|c|}{ CNV genes } & \multicolumn{5}{|c|}{ partners in P1R1 and P1R3 } \\
\hline \multirow{2}{*}{$\begin{array}{l}\text { Entrez } \\
\text { gene ID }\end{array}$} & \multirow{2}{*}{$\begin{array}{l}\text { Official } \\
\text { symbol }\end{array}$} & \multirow{2}{*}{$\begin{array}{c}\text { Total } \\
\text { partners }\end{array}$} & \multicolumn{2}{|c|}{$\begin{array}{r}\text { unique to } \\
1\end{array}$} & \multicolumn{2}{|c|}{$\begin{array}{r}\text { shared } \\
\text { by } 2\end{array}$} \\
\hline & & & count & Freq & count & Freq \\
\hline 8326 & FZD9 & 1 & 0 & 1.000 & 1 & 4.000 \\
\hline 9031 & BAZ1B & 22 & 3 & 0.136 & 19 & 0.864 \\
\hline 9275 & BCL7B & 5 & 4 & 0.800 & 1 & 0.200 \\
\hline 26608 & TBL2 & 16 & 12 & 0.750 & 4 & 0.250 \\
\hline 84277 & DNAJC30 & 8 & 3 & 0.375 & 5 & 0.625 \\
\hline 114049 & WBSCR22 & 3 & 1 & 0.333 & 2 & 0.667 \\
\hline 6804 & STX1A & 16 & 10 & 0.625 & 6 & 0.375 \\
\hline 83451 & ABHD11 & 4 & 4 & 1.000 & 0 & 0.000 \\
\hline 1365 & CLDN3 & 1 & 1 & 1.000 & 0 & 0.000 \\
\hline 1364 & CLDN4 & 1 & 1 & 1.000 & 0 & 0.000 \\
\hline 2006 & ELN & 10 & 8 & 0.800 & 2 & 0.200 \\
\hline 3984 & LIMK1 & 16 & 13 & 0.813 & 3 & 0.188 \\
\hline 7458 & EIF4H & 29 & 10 & 0.345 & 19 & 0.655 \\
\hline 5982 & RFC2 & 42 & 12 & 0.286 & 30 & 0.714 \\
\hline 7461 & CLIP2 & 2 & 0 & 0.000 & 2 & 1.000 \\
\hline 9569 & GTF2IRD1 & 15 & 13 & 0.867 & 2 & 0.133 \\
\hline 2969 & GTF2I & 50 & 17 & 0.340 & 33 & 0.660 \\
\hline
\end{tabular}


ANOVA Test

Summary

\begin{tabular}{|ccccc|}
\hline $\begin{array}{c}\text { Groups } \\
\text { Frequency of } \\
\text { interactors }\end{array}$ & Count & Sum & Average & Variance \\
\hline Unique to 1 network & 17 & 10.469 & 0.616 & 0.122 \\
Shared by 2 network & 17 & 10.531 & 0.619 & 0.122 \\
\hline
\end{tabular}

803

Result

\begin{tabular}{|cccccc|}
\hline $\begin{array}{c}\text { Source of } \\
\text { variation }\end{array}$ & SS & df & MS & F & p-value \\
\hline Between Groups & 0.111 & 1 & 0.1106 & 0.904 & 0.349 \\
Within Groups & 3.912 & 32 & 0.1223 & & \\
Total & 4.023 & 33 & & & \\
\hline
\end{tabular}

804

805

806

807

808

Figure S1. Significant enriched KEGG pathways of seventy-one partners

809 which exclusively from P4R3 network.

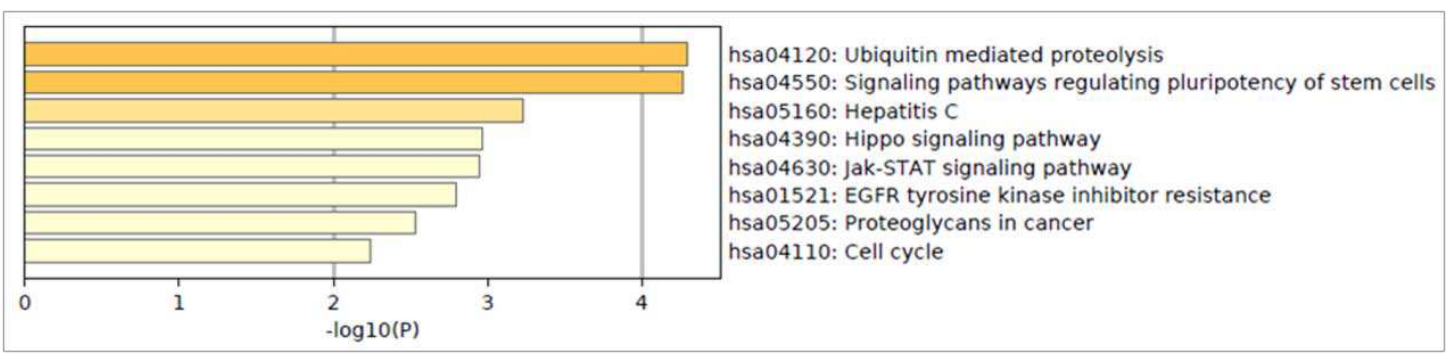




\section{A. Parameters of P1R1 network}

\begin{tabular}{|c|c|c|c|c|}
\hline Entrez gene ID & Gene symbole & Radiality & Degree & Eccentricity \\
\hline 9031 & BAZ1B & 0.7509 & 21 & 5 \\
\hline 9275 & BCL7B & 0.5077 & 2 & 7 \\
\hline 26608 & TBL2 & 0.6505 & 13 & 7 \\
\hline 2006 & ELN & 0.5723 & 8 & 7 \\
\hline 7458 & EIF4H & 0.5791 & 23 & 7 \\
\hline 5982 & RFC2 & 0.7645 & 38 & 5 \\
\hline 9569 & GTF2IRD1 & 0.6386 & 6 & 7 \\
\hline 2969 & GTF2I & 0.7951 & 48 & 5 \\
\hline
\end{tabular}

Note: FZD9, DNAJC30, WBSCR22, STX1A, ABHD11, LIMK1, CLIP2 were excluded because of

\section{B. Parameters of P1R3 network}

\begin{tabular}{|c|c|c|c|c|}
\hline Entrez gene ID & Gene symbole & Radiality & Degree & Eccentricity \\
\hline 9031 & BAZ1B & 0.6125 & 20 & 5 \\
\hline 7458 & EIF4H & 0.6667 & 25 & 5 \\
\hline 5982 & RFC2 & 0.7009 & 34 & 5 \\
\hline 9569 & GTF2IRD1 & 0.6581 & 11 & 5 \\
\hline 2969 & GTF2I & 0.7265 & 35 & 5 \\
\hline
\end{tabular}

\section{Parameters of P4R3 network}

\begin{tabular}{|c|c|c|c|c|}
\hline Entrez gene ID & Gene symbole & Radiality & Degree & Eccentricity \\
\hline 9031 & BAZ1B & 0.6115 & 20 & 5 \\
\hline 26608 & TBL2 & 0.5687 & 11 & 5 \\
\hline 7458 & EIF4H & 0.6025 & 22 & 5 \\
\hline 5982 & RFC2 & 0.6453 & 26 & 5 \\
\hline 9569 & GTF2IRD1 & 0.5980 & 20 & 5 \\
\hline 2969 & GTF2I & 0.8007 & 57 & 3 \\
\hline
\end{tabular}

Note: BCL7B, VPS37D, DNAJC30, WBSCR22, STX1A, ABHD11, ELN, LIMK1, LAT2, CLIP2 
Table S6. Parameters of interacting partners from functional module within P1R1, P1R3, and P4R3 networks.

A. Parameters of interacting partners of functional module within P1R1

\begin{tabular}{|c|c|c|c|c|}
\hline Entrez gene ID & Gene symbol & Radiality & Degree & Eccentricity \\
\hline 5591 & PRKDC & 0.8611 & 7 & 2 \\
\hline 672 & BRCA1 & 0.7500 & 5 & 3 \\
\hline 6117 & RPA1 & 0.7778 & 6 & 3 \\
\hline 6118 & RPA2 & 0.7778 & 6 & 3 \\
\hline 6119 & RPA3 & 0.7500 & 5 & 3 \\
\hline 8452 & CUL3 & 0.6667 & 2 & 3 \\
\hline 8841 & HDAC3 & 0.7778 & 4 & 2 \\
\hline 7706 & TRIM25 & 0.7222 & 3 & 3 \\
\hline 3191 & HNRNPL & 0.6389 & 2 & 3 \\
\hline 9203 & ZMYM3 & 0.5278 & 2 & 3 \\
\hline
\end{tabular}

834

835

B. Parameters of interacting partners of functional module within P1R3

\begin{tabular}{|c|c|c|c|c|}
\hline Entrez gene ID & Gene symbol & Radiality & Degree & Eccentricity \\
\hline 5591 & PRKDC & 0.8864 & 7 & 3 \\
\hline 672 & BRCA1 & 0.8636 & 5 & 2 \\
\hline 6117 & RPA1 & 0.8864 & 7 & 3 \\
\hline 8452 & CUL3 & 0.7500 & 3 & 4 \\
\hline 3191 & HNRNPL & 0.8409 & 4 & 2 \\
\hline 6119 & RPA3 & 0.7273 & 3 & 4 \\
\hline 6118 & RPA2 & 0.8182 & 4 & 3 \\
\hline 8841 & HDAC3 & 0.7045 & 2 & 4 \\
\hline 9203 & ZMYM3 & 0.5227 & 1 & 4 \\
\hline
\end{tabular}

C.Parameters of interacting partners of functional module within P4R3

\begin{tabular}{|c|c|c|c|c|}
\hline Entrez gene ID & Gene symbol & Radiality & Degree & Eccentricity \\
\hline 6117 & RPA1 & 0.8750 & 6 & 2 \\
\hline 8452 & CUL3 & 0.7708 & 3 & 3 \\
\hline 672 & BRCA1 & 0.8125 & 4 & 3 \\
\hline 7750 & ZMYM2 & 0.7292 & 3 & 4 \\
\hline 9203 & ZMYM3 & 0.7500 & 4 & 4 \\
\hline 3191 & HNRNPL & 0.7917 & 3 & 3 \\
\hline 6118 & RPA2 & 0.5000 & 1 & 4 \\
\hline
\end{tabular}




\begin{tabular}{|l|c|c|c|c|}
5591 & PRKDC & 0.8333 & 5 & 3 \\
\hline 8841 & HDAC3 & 0.7292 & 3 & 4 \\
\hline 6119 & RPA3 & 0.6458 & 1 & 3 \\
\hline
\end{tabular}

840

841

842

843

844 One-dimensional SDS-PAGE separation of the immunoprecipitated proteins using 845 control IgG or Myc antibody from HEK293 cells. Several protein bands that are 846 847 848 849 850 851 852 853 854 855 856 857
Figure S2. SDS-PAGE separation of the immunoprecipitated proteins.

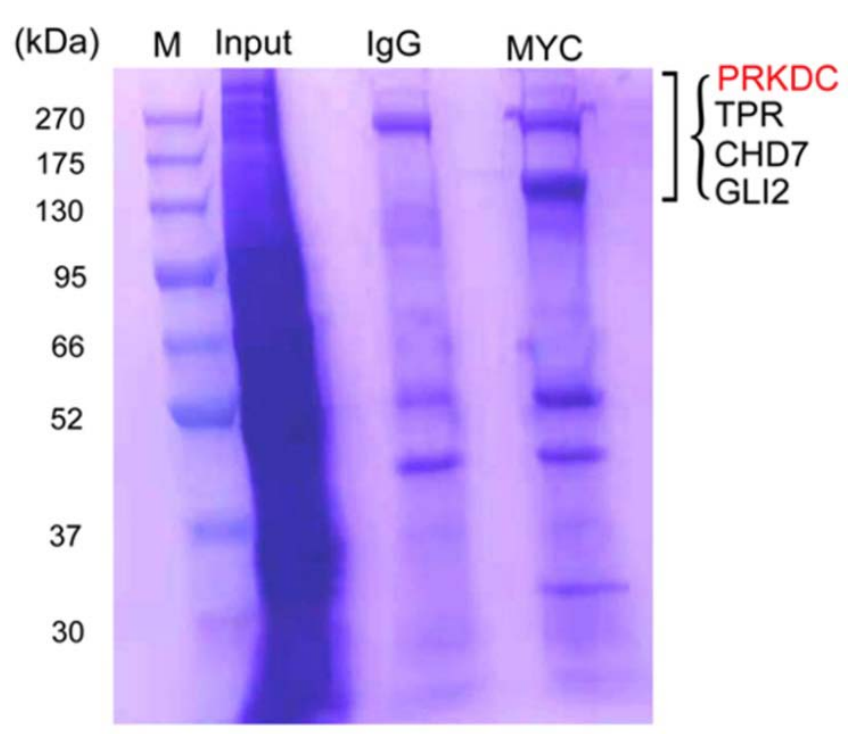
unique which identified by LC-MS/MS were listed on the right side of the panel. 
Table S7. Enrichment analysis of de novo mutations from 7q11.23 spatiotemporal networks

\begin{tabular}{|c|c|c|c|c|}
\hline $\begin{array}{l}\text { Number of genes within } \\
\qquad 7 \mathrm{q} 11.23 \\
\text { spatiotemporal networks }\end{array}$ & $\begin{array}{l}\text { Number of } \\
\text { autism risk } \\
\text { genes }\end{array}$ & $\begin{array}{c}\text { Number of autism risk } \\
\text { genes } \\
\text { in spatiotemporal } \\
\text { networks }\end{array}$ & $\begin{array}{l}\text { Fisher } \\
\text { exact } \\
\text { p-value }\end{array}$ & Benjamini-Hochberg \\
\hline 635 & 239 & 20 & 0.00012 & 0.00072 \\
\hline
\end{tabular}

860

\begin{tabular}{|c|c|c|c|c|}
\hline $\begin{array}{l}\text { Number of genes } \\
\text { within } 7 \mathrm{q} 11.23 \\
\text { spatiotemporal } \\
\text { networks }\end{array}$ & $\begin{array}{l}\text { Number of } \\
\text { developmental } \\
\text { delay genes }\end{array}$ & $\begin{array}{c}\text { Number of } \\
\text { developmental delay } \\
\text { genes in } \\
\text { spatiotemporal } \\
\text { networks }\end{array}$ & Fisher exact & Benjamini-Hochberg \\
\hline 635 & 1302 & 60 & 0.00302 & $p=0.00450$ \\
\hline
\end{tabular}

861

\begin{tabular}{|c|c|c|c|c|}
\hline $\begin{array}{c}\text { Number of genes within } \\
7 \mathrm{q} 11.23 \\
\text { spatiotemporal } \\
\text { networks }\end{array}$ & $\begin{array}{c}\text { Number of fragile } \\
\mathrm{X} \mathrm{mental} \\
\text { retardation } \\
\text { protein (FMRP) }\end{array}$ & $\begin{array}{c}\text { Number of FMRP } \\
\text { genes } \\
\text { in spatiotemporal } \\
\text { networks }\end{array}$ & $\begin{array}{c}\text { Fisher } \\
\text { exact } \\
\mathrm{p} \text {-value }\end{array}$ & Benjamini-Hochberg \\
\hline 635 & 839 & 45 & 0.00057 & $\mathbf{p = 0 . 0 0 1 7 0}$ \\
\hline
\end{tabular}

862

\begin{tabular}{|c|c|c|c|c|}
\hline $\begin{array}{c}\text { Number of genes } \\
\text { within 7q11.23 }\end{array}$ & Number of & $\begin{array}{c}\text { Number of } \\
\text { neurodegenerative } \\
\text { disease genes } \\
\text { spatiotemporal } \\
\text { networks }\end{array}$ & $\begin{array}{c}\text { Fisher } \\
\text { exact } \\
\text { neurodegenerative } \\
\text { disease genes }\end{array}$ & Benoral \\
\hline 635 & 93 & 7 & 0.03124 & p-value \\
\hline
\end{tabular}




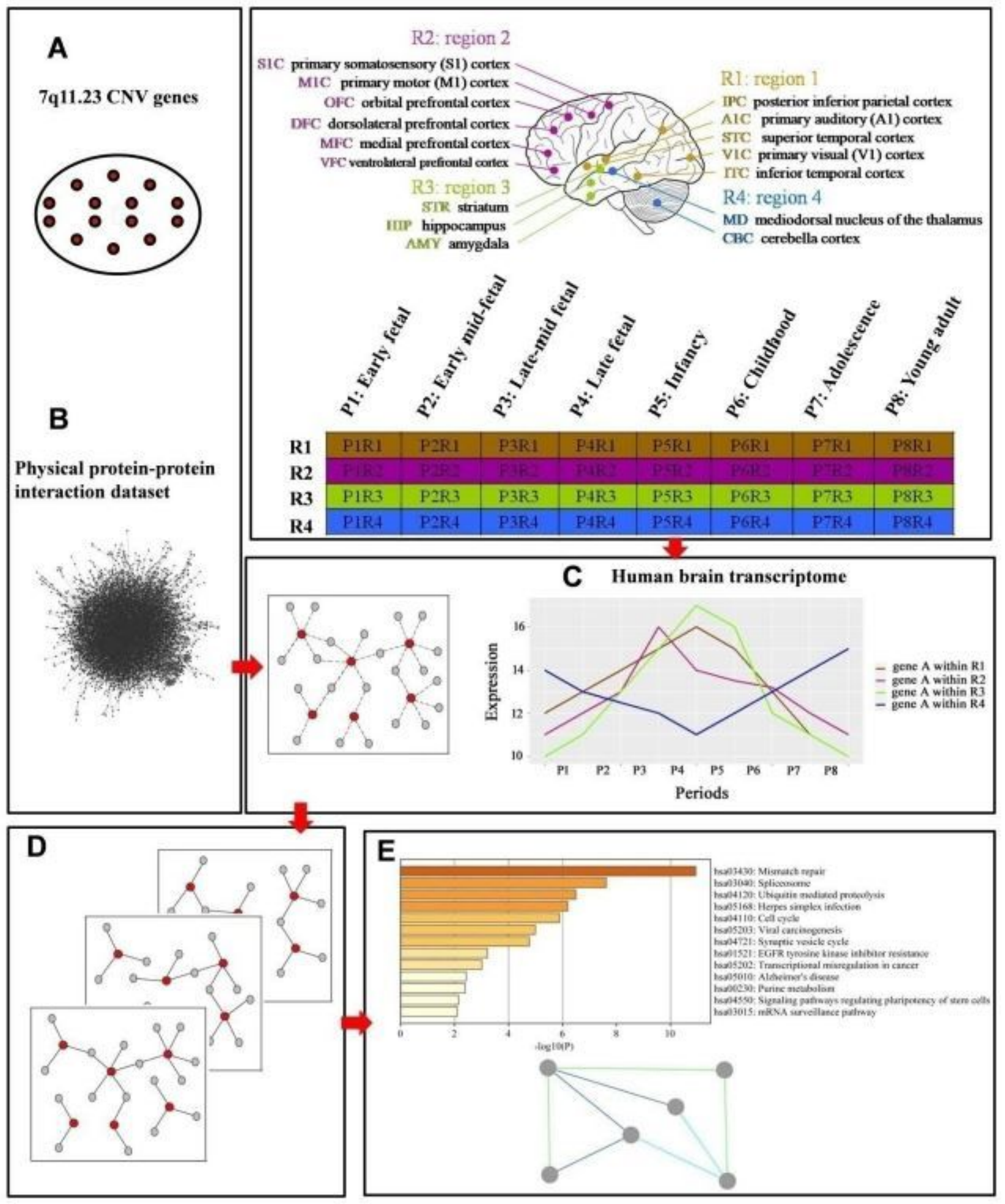

\section{Figure 1}

A flow-chart shows the plan of work involved in this research study. (A) Twenty-three 7q11.23 CNV genes expressed in the brain were identified. (B) Physical protein-protein interaction dataset combined with 7q11.23 CNV genes to construct CNV protein-protein interactions (PPIs). (C) 7q11.23 CNV PPIs combined 
with the Human brain transcriptome dataset. (D) 7q11.23 spatiotemporal co-expression PPIs network was established. (E) Functional enrichment analysis and functional module analysis were performed.

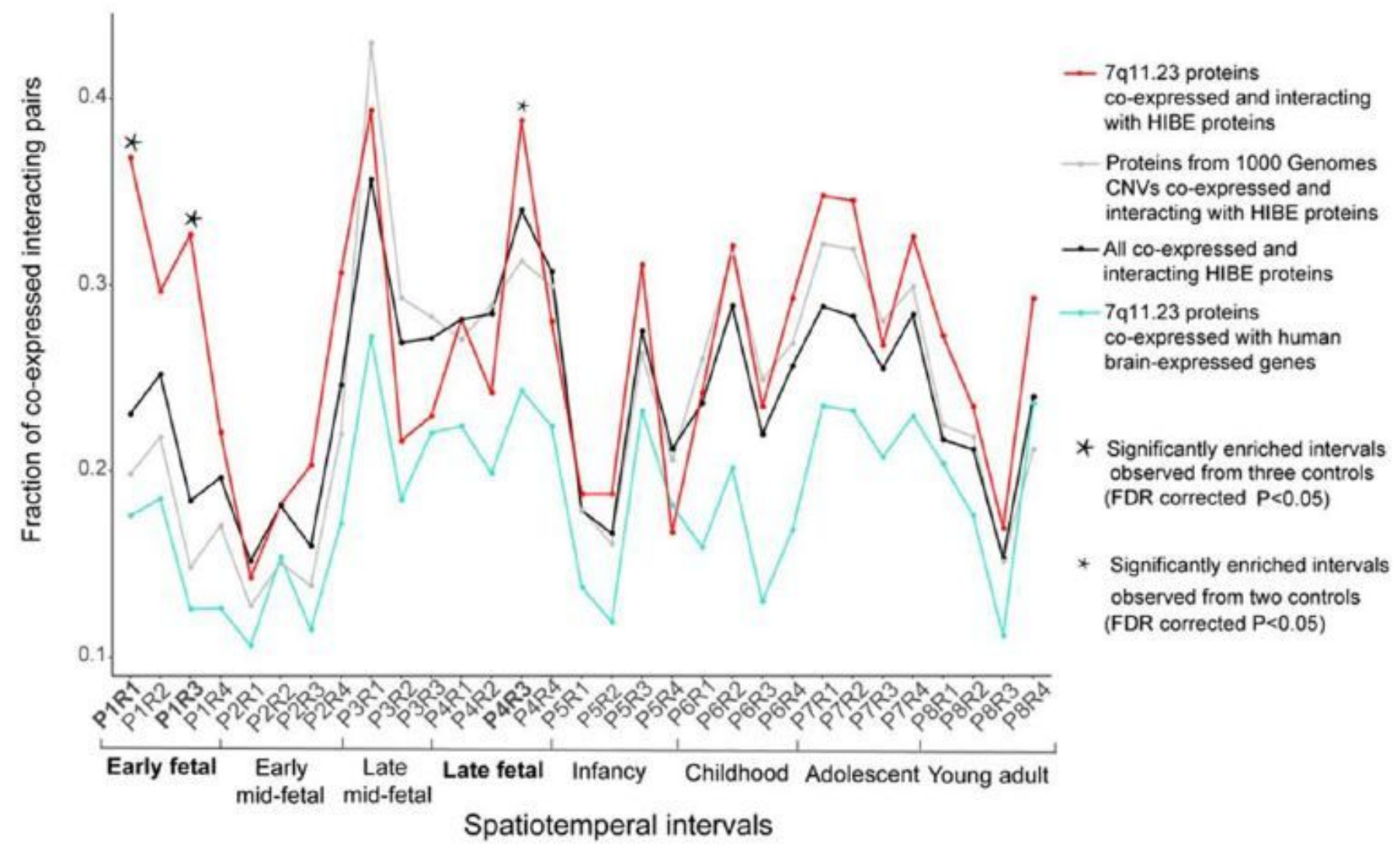

Figure 2

The 7q11.23 co-expressed interacting protein pairs are significantly enriched in three spatiotemporal intervals. The fractions of protein pairs from 7q11.23 CNV co-expressed and interacting with HIBE proteins (red line), all co-expressed and interacting HIBE proteins (black line), proteins from 1000 Genome Project CNVs co-expressed and interacting with HIBE proteins (dark gray line), and 7q11.23 CNV proteins co-expressed with all brain-expressed human genes (aquamarine line). Thirty-one spatiotemporal intervals of brain development are shown on the x-axis. 7q11.23 co-expressed interacting protein pairs are significantly enriched in spatiotemporal intervals (indicated by star symbol) compared with control networks. The statistical enrichment was calculated using Fisher's exact test, and $p$ values were FDRcorrected for multiple comparisons. 


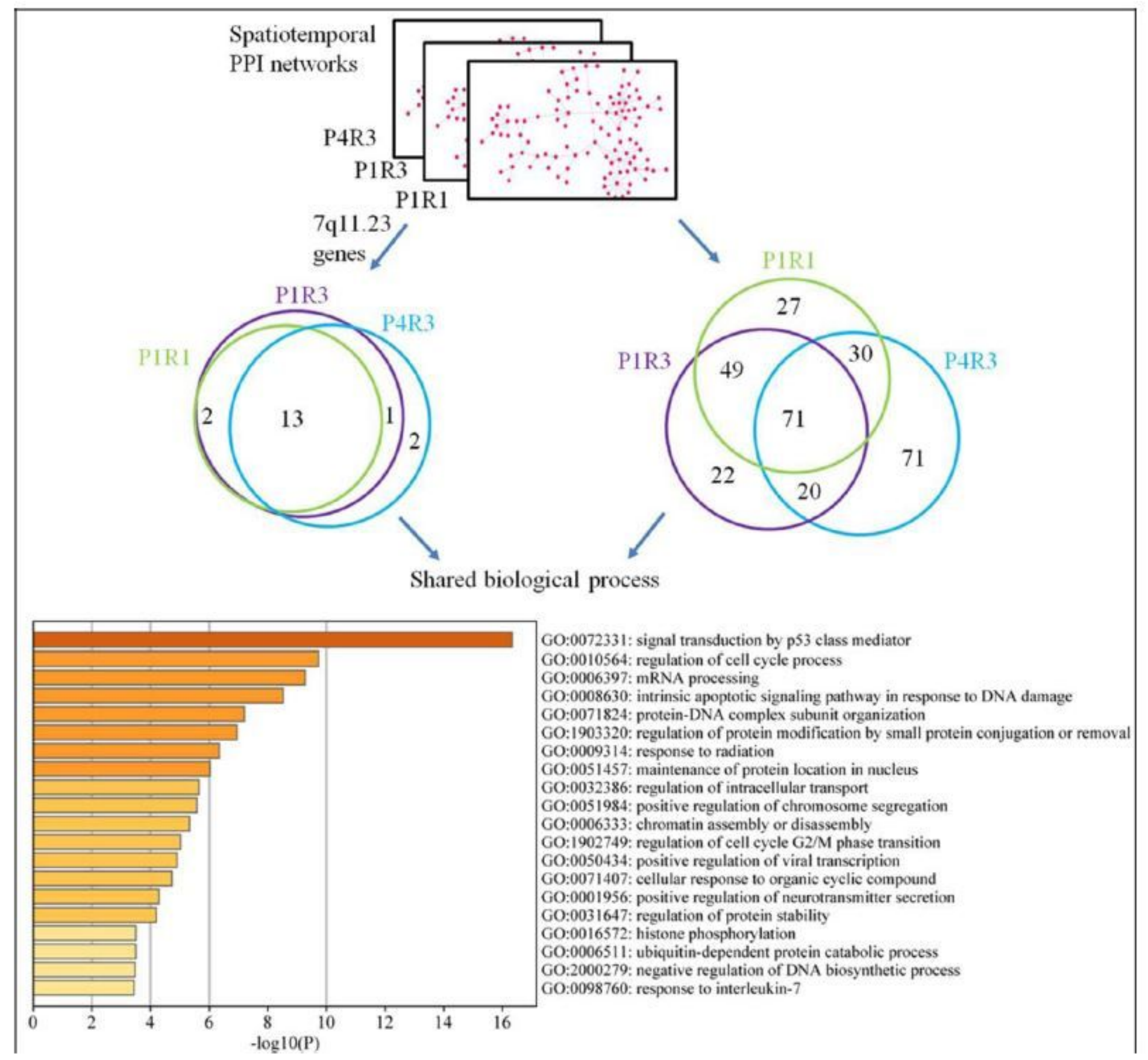

Figure 3

Functional convergence of the 7q11.23 spatiotemporal networks. The overlap of 7q11.23 genes (left Venn diagram) and their co-expressed interacting partners (right Venn diagram) across three significant spatiotemporal intervals. Top 20 significant enriched biological process $\mathrm{GO}$ terms of shared proteins are showed. 


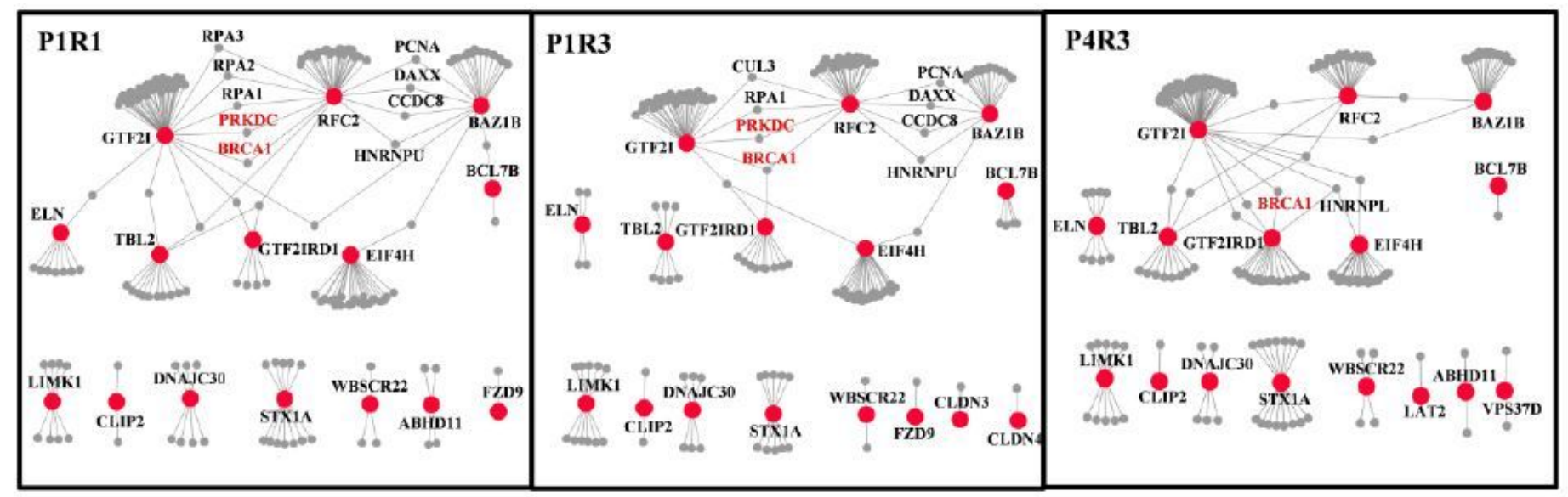

\begin{tabular}{cccccc}
\hline ANOVA tests & sum of squares & df & mean square & F & P-values \\
\hline P1R1 and P1R3 & 0.111 & 1 & 0.1106 & 0.904 & 0.349 \\
\hline P1R3 and P4R3 & 3.686 & 1 & 3.686 & 105.7 & $\mathbf{2 . 9 5} \times \mathbf{1 0}-12 * * *$ \\
\hline
\end{tabular}

\section{Figure 4}

Difference between the 7q11.23 spatiotemporal networks. Comparison of spatiotemporal networks across different brain regions within the same developmental period (P1R1 and P1R3) and cross different development periods within the same brain region (P1R3 and P4R3). 7q11.23 genes are shown as red nodes, their co-expressed interacting partners as gray node, and the PPIs between co-expressed genes at a particular developmental period are shown as gray edges. The nodes that lost all edges were removed from the corresponding networks. Significant differences are observed across developmental periods but not across brain regions (ANOVA statistics shown below the graphs). 


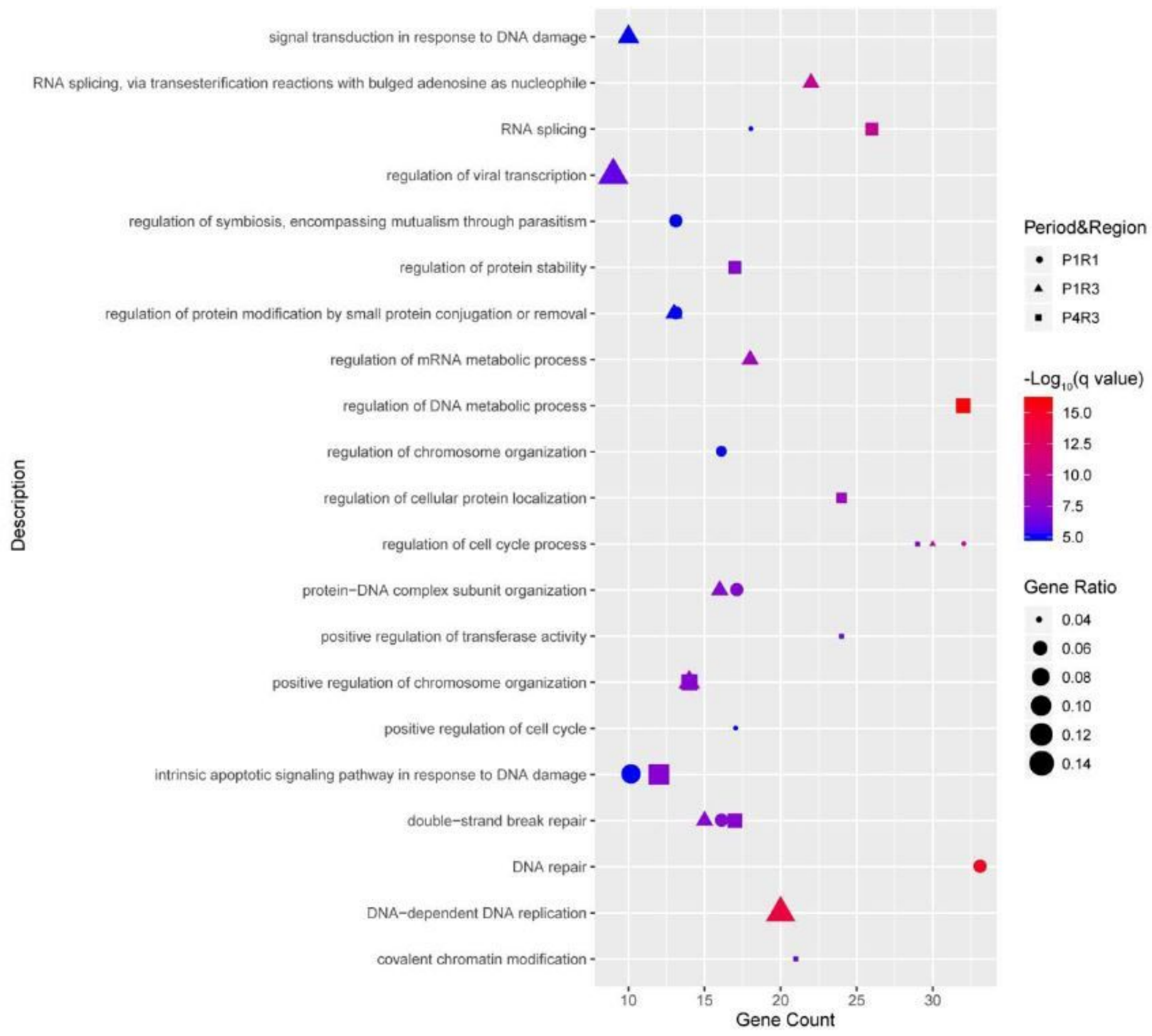

Figure 5

Functional analyses of proteins within three significant intervals, P1R1, P1R3 and P4R3. Dot plot shows top 10 enriched $\mathrm{GO}$ terms of biological process for CNV proteins and their partners within three significant intervals. 